\title{
Viabilidade do emprego de cinza de casca de arroz natural em concreto estrutural (parte II): durabilidade
}

\author{
The feasibility of using natural rice husk ash in structural \\ concrete (part II): durability
}

\section{Geraldo Cechella Isaia \\ Raúl Luis Zerbino \\ Antonio Luiz Guerra Gastaldini \\ Gemma Rodrigues Sensale}

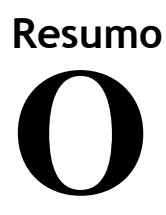
aumentar a finura e a reatividade com o cimento, quando empregada como material cimentício. Este trabalho estuda cinza de casca de arroz natural (CCAN) sem processamento em substituição parcial de $15 \%$ de cimento, em massa, para uso em concreto estrutural, cominuída por moagem conjunta com os agregados no tambor da betoneira. Na parte I desta pesquisa, já publicada, são apresentados os resultados de microestrutura, resistência mecânica e retração, também para o teor de $25 \%$, e nesta parte II são mostrados os dados dos ensaios de durabilidade (carbonatação, penetração de cloretos, resistividade, absorção d'água, permeabilidade ao oxigênio, absorção capilar e reação álcali-sílica - RAS), comparados ao concreto referência com $100 \%$ de cimento e, ainda, com CCA moída previamente (CCAM). Os resultados mostram que 15\% de CCAN é factível de ser empregado em concreto porque apresenta desempenho superior ao concreto referência, quando usado cimento com pozolanas e próximos ou até superiores às misturas de CCAM, para grande parte das variáveis estudadas. Conclui-se que $15 \%$ de CCAN para concreto estrutural é viável e traz maior sustentabilidade.

Palavras-chaves: Cinza de casca de arroz natural. Cinza de casca de arroz moída. Durabilidade. Sustentabilidade. RAS.

Geraldo Cechella Isaia Universidade Federal de Santa Maria Santa Maria - RS - Brasil

Raúl Luis Zerbino Comisión de Investigaciones Científicas La Plata - Buenos Aires - Argentina

Antonio Luiz Guerra Gastaldini Universidade Federal de Santa Maria Santa Maria - RS - Brasil

Gemma Rodrigues Sensale Universidad de la República Montevideo - Uruguay

Recebido em 03/01/15 Aceito em 03/11/16

\section{Abstract}

Waste incorporated in construction materials should be used, whenever possible, without processing in order to avoid environmental impact and additional costs. Rice husk ash (RHA) is a pozzolan that must be ground before use in order to increase its fineness and reactivity with Portland cement when it is used as a cementitious material. This study investigates natural rice husk ash (NRHA), without processing, replacing $15 \%$ of Portland cement, in mass. The NRHA was ground together with the aggregates in the mixer drum. Part I of this study presented the test results regarding microstructure, mechanical strength and shrinkage, including 25\% content; Part II presents durability test results (carbonation, chloride penetration, electrical resistivity, water absorption, oxygen permeability and alkali-silica reaction - ASR), compared with a reference concrete with $100 \%$ cement and with ground RHA (GRHA). The results showed that it is feasible to use 15\% NRHA in concrete, as it presents higher performance when cement with pozzolans is used, and near or even better performance than GRHA mixtures for most of the variables analysed. The study concludes that $15 \%$ of NRHA in structural concrete is feasible and produces a more sustainable material. Keywords: Natural rice husk ash. Ground rice husk ash. Durability. Sustainability. ASR. 


\section{Introdução}

O cimento Portland, juntamente com seus derivados, é o material de construção industrializado mais consumido no mundo, porque é empregado em toda a cadeia do processo construtivo, especialmente no concreto estrutural. A produção mundial de cimento alcançou 4,0.1012 t (CEMBUREAU, 2014), sendo 70,2.109 t no Brasil (SNIC, 2014), dados de 2013. Apesar dos esforços para a modernização das plantas de fabricação, a indústria cimenteira é responsável por quase $6 \%$ das emanações globais dos gases do efeito estufa.

Para diminuir os impactos que a fabricação e uso do cimento exercem sobre o meio ambiente, a solução tem sido a substituição parcial do clinquer por pozolanas de origem industrial como cinza volante, sílica ativa ou metacaulim ou resíduos agrícolas como cinza de casca de arroz, cinza de bagaço de cana, entre outros.

O arroz é cultivado em mais de 100 países, com produção de 743.106 t (FOOD..., 2013), sendo o Brasil o décimo produtor mundial, com $12.106 \mathrm{t}$, e o Rio Grande do Sul o responsável por dois terços desse total, com $8.106 \mathrm{t}$, dados da safra 2013-2014 (INSTITUTO..., 2013). Ao redor de 4,8\% da massa de arroz é transformada em casca e, após a queima, em cinzas, utilizadas em algumas aplicações industriais ou descartadas como resíduo, somando uma produção potencial de CCA de quase $35.106 \mathrm{t}$ no mundo e de 0,6.106 $\mathrm{t}$ no Brasil.

O teor da sílica da CCA, quase sempre acima de $90 \%$, quando queimada com controle de temperatura para obtenção de microestrutura amorfa, é apropriado para uso em concreto de alto desempenho, competindo com a sílica ativa, quando finamente moída. Estima-se que a maior parte da produção de CCA tenha aplicações secundárias devido à queima sem controle de temperatura, o que lhe confere algum grau de cristalinidade, sendo então considerada cinza residual, devido à menor reatividade pozolânica. Assim, quantidades representativas de CCA não são utilizadas para fins mais nobres, como na substituição parcial de clínquer, sendo então lançadas em aterros e causando poluição ambiental em cursos d'água ou aquíferos.

Após os anos 1970 foram publicadas pesquisas sobre o uso da CCA em concreto em substituição ao cimento Portland (MEHTA; PITT, 1976; JAMES; RAO, 1986; ZHANG; MALHOTRA, 1996), em vista do incremento das propriedades mecânicas e durabilidade que possibilita (MEHTA, 1987; NEHDI; DUQUETTE; EL DAMATTY,
2003). Esses efeitos benéficos são proporcionados pela porosidade interna dos grãos da CCA e pela finura e atividade pozolânica, que propiciam o refinamento dos poros e dos grãos de hidróxido de cálcio $\mathrm{CH}$ da pasta cimentícia (MEHTA; MONTEIRO, 2008).

Para maior conhecimento e ampliação do uso de CCA residual em substituição ao clínquer, a partir de 1990 foram desenvolvidas pesquisas tanto internacionais (SUGITA; SHOYA; TOKUDA, 1992; RODRIGUES, 2003; TUAN, 2012) quanto nacionais (ISAIA, 1995; SENSALE, 2000; RÊGO, 2004; POUEY, 2006; CORDEIRO, 2011), para utilizá-la em concreto estrutural em regiões perto de onde é produzida. Esses trabalhos revelaram, de modo geral, o bom desempenho dessa pozolana, apesar de queimada sem controle de temperatura, ante as propriedades mecânicas ou a durabilidade.

A finura dos materiais cimentícios é um dos principais fatores que governam a velocidade das reações entre as partículas (ação química) e a obturação dos poros por efeito físico, ocasionando aumento da compacidade da matriz e, logo, do desempenho mecânico, da durabilidade e da vida útil quando utilizada em estruturas de concreto. Essa constatação não invalida o estudo da viabilidade do uso de adições minerais não tão finas quanto desejável, desde que técnica e economicamente comprovado, visto que maior finura implica gastos energéticos adicionais ou processamentos industriais complementares, os quais aumentam o custo de produção e diminuem os ganhos de sustentabilidade diante dos impactos ambientais de resíduos que deveriam ser empregados preferencialmente in natura.

Hwang e Chandra (2002) afirmam que a atividade pozolânica com cal ou cimento não implica grãos de CCA muito finos, em vista da alta superfície específica interna da estrutura microporosa das partículas individuais, e ainda declaram que grãos maiores, entre $10 \mu \mathrm{m}$ e $75 \mu \mathrm{m}$, apresentam reatividade química satisfatória. Nos últimos anos realizaram-se pesquisas sobre concretos com CCA natural com finura mais grossa, como os estudos de Brown (2012), com diâmetros de partículas > $100 \mu \mathrm{m}$, e de Quamruddin e Kalurkar (2013), com diâmetros < $90 \mu \mathrm{m}$, cujos resultados foram promissores para o desempenho mecânico e a durabilidade.

Ao contrário da reconhecida qualidade e reatividade das CCAs queimadas com controle de temperatura e moídas previamente (CCAM) para uso em concretos, esta pesquisa estuda a viabilidade técnica da CCA natural (CCAN) sem

234 Isaia, G. C.; Zerbino, R. L.; Gastaldini, A. L. G.; Sensale, G. R. 
prévia moagem e como recebida dos engenhos de beneficiamento após a queima, sem controle de temperatura. Nas misturas de concreto o cimento Portland foi substituído parcialmente por $15 \%$ de CCAN para uso em obras executadas próximo a locais onde é produzida, com vistas à diminuição de transportes e à redução dos impactos ambientais. O aumento da finura da CCAN foi obtido por moagem em betoneira convencional de eixo inclinado, juntamente com os agregados, em tempo e ordem de colocação dos materiais previamente estudados, com o emprego da mesma estratégia utilizada por Quamruddin e Kalurkar (2013) para a cominuição dos grãos.

Este trabalho apresenta resultados dos ensaios de durabilidade de concretos com CCAN, constituindo-se na segunda parte de pesquisa mais ampla desenvolvida pela UFSM, em Santa Maria, Brasil, pela Udelar, de Montevidéu, Uruguai, e pelo Lemit, de La Plata, Argentina, em cuja primeira parte (ISAIA et al., 2010) foram publicados os dados obtidos nos ensaios de microestrutura da pasta, das propriedades mecânicas e retração do concreto, com os mesmos materiais desta investigação.

\section{Materiais e métodos}

\section{Materiais cimentícios}

Utilizou-se cimento Portland do tipo CPIIF-32 (cimento Portland composto com fíler conforme a NBR 11578 (ABNT, 1991)) para os ensaios de resistência mecânica e de durabilidade, e para o ensaios das reações álcali-sílica (RAS) os cimentos CPIIZ-32 (cimento Portland com pozolanas conforme a NBR 11578 (ABNT, 1991)). As cinzas de casca de arroz CCAN foram fornecidas por engenhos de arroz da região, coletadas nos pátios de estocagem, após a queima sem controle de temperatura. Para efeito comparativo, parte dessa cinza foi moída por uma hora em moinho de bolas (CCAM). A CCAN sofreu moagem conjunta com os agregados na betoneira, a seco, na mesma quantidade dos traços de concreto no teor de $15 \%$ em substituição ao cimento.

O estudo experimental das ordenações de colocação dos materiais no tambor e os tempos de mistura que produziram as melhores resistências à compressão axial e os menores teores de material retido no ensaio de peneiramento constam da parte I desta pesquisa (ISAIA et al., 2010), o que corresponde a um tempo total de mistura de 15' para CCAN e de 10' para CCAM.

A Tabela 1 apresenta os resultados das características químicas e físicas dos materiais cimentícios, observando-se que os teores de
$\mathrm{SiO}_{2}+\mathrm{Al}_{2} \mathrm{O}_{3}+\mathrm{Fe}_{2} \mathrm{O}_{3} \geq 95 \%, \mathrm{SO}_{3} \leq 0,02 \%$, P.F. $\leq 0,6 \%$ e álcalis totais $\leq 1,1 \%$ para as CCA moída e natural atenderam aos requisitos da NBR 12653 (ABNT, 2012). A CCAM atendeu ao limite retido na peneira de $45 \mu \mathrm{m}<20 \%$, entretanto a CCAN não $(\approx 82 \%)$, porém, quando moída conjuntamente com os agregados, o teor nesta peneira baixou para $\approx 9,1 \%$.

A Tabela 1 apresenta também as características químicas e físicas da cinza volante empregada nos ensaios de RAS, utilizada para substituir parte do cimento CPIIZ com o intuito de verificar a redução das reações expansivas, no caso de somente com cimento Portland composto com pozolanas não ser suficiente para rebaixar essas reações em níveis inferiores ao previsto pela norma.

A CCAN apresentou massa específica $48 \%$ menor do que a CCAM e, após a moagem na betoneira (CCAN15), apenas $7 \%$ menor. $\mathrm{O}$ diâmetro médio da CCAN15 foi maior que o dobro da CCAM, o que mostra a menor cominuição da moagem na betoneira, resultado da menor energia aplicada na fragmentação dos grãos. Os diâmetros médios da CCAM e CCAN15, após a moagem na betoneira, ficaram no intervalo declarado por Hwang e Chandra (2002) para cinzas residuais. O ensaio de DR-X evidenciou halo de amorfização e picos de cristobalita, conferindo certa cristalinidade à CCA, em razão de sua queima sem controle de temperatura.

As superfícies específicas BET de 19,67 m²/g e de $44,41 \mathrm{~m}^{2} / \mathrm{g}$ respectivamente para a CCAM e a CCAN15 foram menores do que a metade na primeira em relação à segunda, enquanto os diâmetros médios foram de $15,5 \mu \mathrm{m}$ e de $33,2 \mu \mathrm{m}$, isto é, a segunda com mais do dobro da primeira, valores aparentemente antagônicos em relação à área BET x $\varphi_{\text {médio. }}$ A explicação mais provável é a manutenção da estrutura interna mais porosa dos grãos da CCAN15, o que elevaria a superfície BET por causa dos vazios internos, enquanto a cominuição da cinza moída quebraria grande parte dessa estrutura interior mais porosa, diminuindo não só as dimensões dos grãos como sua superfície interna. Essa tendência foi observada na porosimetria por intrusão de $\mathrm{Hg}$, em que a cinza natural apresentou teor mais alto de macroporos > $50 \mu \mathrm{m}$ do que a cinza moída, conforme dados da primeira parte deste trabalho (ISAIA et al., 2010).

O Quadro 1 apresenta os resultados do ensaio de pozolanicidade para cimento Portland pozolânico (ensaio de Fratini), conforme a NBR 5753 (ABNT, 2010), para determinar a reatividade pozolânica da CCAN15 e da CCAM15, ou seja, quando foi substituído $15 \%$ do cimento CPIIZ pela mesma 
massa das duas cinzas de casca de arroz, natural e moída.

Observa-se no Quadro 1 que a CCAM15 diminuiu mais o teor de cal remanescente e reduziu a alcalinidade total da solução do que a CCAN15, o que demonstra maior reatividade pozolânica desta última devido à menor dimensão das partículas, conforme mostra a Tabela 1. É apresentado também o índice de atividade pozolânica (IAP) calculado a partir da curva isotérmica que separa a solução de adições minerais não pozolânicas das pozolânicas, determinado pelo inverso da distância $d$, que separa o ponto de cada mistura no gráfico, em relação à origem das coordenadas.

\section{Agregados}

Empregaram-se duas areias naturais quartzosas, fina e grossa, na proporção de $50 \%$, enquadradas na zona utilizável da NBR 7211 (ABNT, 2005), provenientes de Santa Maria, RS, secas em estufa, peneiradas na \#4,8 $\mathrm{mm}$ e estocadas em cubas de alvenaria. A massa específica média foi de 2,62 $\mathrm{kg} / \mathrm{dm}^{3}$, o módulo de finura de 2,35 , e a dimensão máxima característica de $4,8 \mathrm{~mm}$. Utilizaram-se britas diabásicas de Itaara, RS, classificadas como 1 e 2, utilizadas na proporção de $50 \%$, de acordo com a NBR 7211, lavadas e peneiradas entre \#19 $\mathrm{mm}$ e \#6,3 $\mathrm{mm}$, secas ao ar e estocadas, com massa específica média de $2,52 \mathrm{~kg} / \mathrm{dm}^{3}, \mathrm{MF}=6,17$ e $D_{\text {máx }}=19 \mathrm{~mm}$.

\section{Concreto}

A Tabela 2 mostra a quantidade de materiais, em $\mathrm{kg} / \mathrm{m}^{3}$, dos traços de concreto utilizados.

Tabela 1 - Características físicas dos materiais cimentícios

\begin{tabular}{|c|c|c|c|c|c|c|c|}
\hline \multicolumn{2}{|c|}{ Propriedades/cimentos e CCA } & CPIIF & CPIIZ & CCAM $^{1}$ & $\mathrm{CCAN}^{2}$ & CCAN15 $^{3}$ & C.V. ${ }^{4}$ \\
\hline $\begin{array}{c}\text { Composição } \\
\text { química }\end{array}$ & $\begin{array}{c}\mathrm{CaO} \\
\mathrm{SiO}_{2} \\
\mathrm{Al}_{2} \mathrm{O}_{3} \\
\mathrm{Fe}_{2} \mathrm{O}_{3} \\
\mathrm{SO}_{3} \\
\mathrm{MgO} \\
\mathrm{K}_{2} \mathrm{O} \\
\mathrm{TiO}_{2} \\
\mathrm{Na}_{2} \mathrm{O} \\
\mathrm{SrO} \\
\mathrm{P}_{2} \mathrm{O}_{5} \\
\mathrm{MnO} \\
\text { Perda ao fogo } \\
\mathrm{CaO} \text { livre }\end{array}$ & $\begin{array}{c}60,15 \\
18,92 \\
4,32 \\
2,58 \\
3,19 \\
4,91 \\
1,33 \\
0,41 \\
0,17 \\
0,08 \\
0,10 \\
0,12 \\
1,31 \\
1,85\end{array}$ & $\begin{array}{c}50,84 \\
21,92 \\
6,33 \\
3,27 \\
2,53 \\
5,70 \\
1,17 \\
0,26 \\
0,16 \\
0,10 \\
0,09 \\
0,10 \\
5,46 \\
2,00\end{array}$ & $\begin{array}{c}1,32 \\
94,84 \\
0,39 \\
0,54 \\
0,01 \\
0,40 \\
1,45 \\
\text { n.d. } \\
0,11 \\
\text { n.d. } \\
\text { n.d. } \\
\text { n.d. } \\
\text { 0,94 } \\
\text { n.d. }\end{array}$ & $\begin{array}{c}1,25 \\
95,04 \\
0,00 \\
0,44 \\
0,01 \\
0,45 \\
1,40 \\
\text { n.d. } \\
0,09 \\
\text { n.d. } \\
\text { n.d. } \\
\text { n.d. } \\
1,22 \\
\text { n.d. }\end{array}$ & $\begin{array}{l}\text { Não } \\
\text { determi- } \\
\text { nados }\end{array}$ & $\begin{array}{c}2,85 \\
67,08 \\
21,29 \\
4,44 \\
0,14 \\
0,87 \\
2,05 \\
\text { n.d. } \\
0,40 \\
\text { n.d. } \\
\text { n.d. } \\
\text { n.d. } \\
0,60 \\
\text { n.d. }\end{array}$ \\
\hline Físicas & $\begin{array}{l}\text { Massa esp., } \mathrm{kg} / \mathrm{dm}^{3} \\
\text { Sup. esp. BET, } \mathrm{m}^{2} / \mathrm{g} \\
\text { S. esp. Blaine, } \mathrm{cm}^{2} / \mathrm{g} \\
\text { Resíd. \#0,045 mm, \% }\end{array}$ & $\begin{array}{l}3,06 \\
1,44 \\
4610 \\
2,98\end{array}$ & $\begin{array}{l}2,96 \\
\text { n.d. } \\
5240 \\
\text { n.d. }\end{array}$ & $\begin{array}{c}2,09 \\
19,67 \\
4501 \\
4,97 \\
\end{array}$ & $\begin{array}{c}1,41 \\
49,25 \\
4441 \\
82,18\end{array}$ & $\begin{array}{c}1,96 \\
44,41 \\
\text { n.d. } \\
9,09\end{array}$ & $\begin{array}{l}1,96 \\
\text { n.d. } \\
2310 \\
\text { n.d. }\end{array}$ \\
\hline $\begin{array}{l}\text { Granulo- } \\
\text { metria } \\
\text { a laser }\end{array}$ & $\begin{array}{l}\text { Diâmetro médio, } \mu \mathrm{m} \\
\text { Diâmetro<10\%, } \mu \mathrm{m} \\
\text { Diâmetro<90\%, } \mu \mathrm{m}\end{array}$ & $\begin{array}{c}11,5 \\
1,3 \\
41,6\end{array}$ & $\begin{array}{c}7,7 \\
1,0 \\
27,5\end{array}$ & $\begin{array}{c}15,5 \\
2,4 \\
54,1\end{array}$ & $\begin{array}{l}\text { n.d. } \\
\text { n.d. } \\
\text { n.d. }\end{array}$ & $\begin{array}{c}33,2 \\
5,2 \\
80,5\end{array}$ & $\begin{array}{c}41,3 \\
5,0 \\
261,1\end{array}$ \\
\hline
\end{tabular}

Nota: ${ }^{1}$ CCAM: CCA moída por $1 \mathrm{~h}$ em moinho de bolas; ${ }^{2}$ CCAN: CCA natural, como recebido do engenho; ${ }^{3}$ CCAN15: CCA natural no teor de $15 \%$, moída na betoneira com os agregados; e ${ }^{4} \mathrm{C} . V$. .: cinza volante.

Quadro 1 - Índice de atividade pozolânica (Fratini)

\begin{tabular}{|c|c|c|c|c|}
\hline \multirow{2}{*}{ Misturas } & \multicolumn{2}{|c|}{ Atividade pozolânica } & \multirow{2}{*}{ Distância ("d"cm) } & \multirow{2}{*}{$\begin{array}{c}\text { Índice de atividade } \\
\text { pozolânica }{ }^{1} \text { IAP }\end{array}$} \\
\hline & mmol CaO/l & $\mathrm{mmol} \mathrm{OH}^{-} / \mathrm{l}$ & & \\
\hline CPIIF & 8,0 & 59 & 6,8 & 14,7 \\
\hline CCAN15 & 9,0 & 48 & 6,0 & 16,7 \\
\hline CCAM15 & 6,0 & 43 & 5,2 & 19,2 \\
\hline
\end{tabular}

Nota: ${ }^{1} \mathrm{~d}=$ distância de cada ponto no gráfico $(\mathrm{mmol} \mathrm{CaO} / \mathrm{l} \times \mathrm{mmol} \mathrm{OH}-/ \mathrm{l})$ à origem das coordenadas. Índice IAP=1.d 1.100 , conforme Isaia $(1995,1997)$ e Isaia, Gastaldini e Moraes (2003). 
Tabela 2 - Quantidade de materiais dos traços

\begin{tabular}{|c|c|c|c|c|c|c|c|c|}
\hline Traços & $\begin{array}{c}\text { CCA } \\
\%\end{array}$ & $\begin{array}{c}\text { Relação a/mc } \\
\mathrm{kg} / \mathrm{kg}\end{array}$ & $\begin{array}{c}\text { Cimento } \\
\mathrm{kg} / \mathrm{m}^{3}\end{array}$ & $\begin{array}{c}\mathrm{CCA} \\
\mathrm{kg} / \mathrm{m}^{3}\end{array}$ & $\begin{array}{l}\text { Areia } \\
\mathrm{kg} / \mathrm{m}^{3}\end{array}$ & $\begin{array}{l}\text { Brita } \\
\mathrm{kg} / \mathrm{m}^{3}\end{array}$ & $\begin{array}{c}\begin{array}{c}\text { Água } \\
\mathrm{dm}^{3} / \mathbf{m}^{3}\end{array} \\
\end{array}$ & $\begin{array}{l}\text { Aditivo } \\
\mathbf{d m}^{3} / \mathbf{m}^{3} \\
\end{array}$ \\
\hline \multirow{3}{*}{ REF } & - & 0,45 & 407 & - & 688 & 1095 & 183 & 0,1 \\
\hline & - & 0,55 & 320 & - & 779 & 1095 & 176 & 0,3 \\
\hline & - & 0,65 & 263 & - & 838 & 1101 & 171 & 0,1 \\
\hline \multirow{3}{*}{ M15 } & \multirow{3}{*}{15} & 0,45 & 346 & 61,1 & 664 & 1095 & 183 & 1,3 \\
\hline & & 0,55 & 272 & 47,9 & 760 & 1095 & 176 & 1,4 \\
\hline & & 0,65 & 223 & 39,4 & 822 & 1101 & 171 & 1,2 \\
\hline \multirow{3}{*}{ N15 } & \multirow{3}{*}{15} & 0,45 & 346 & 61,1 & 627 & 1095 & 183 & 2,2 \\
\hline & & 0,55 & 272 & 47,9 & 732 & 1095 & 176 & 2,1 \\
\hline & & 0,65 & 223 & 39,4 & 799 & 1101 & 171 & 2,2 \\
\hline & & & & & & & & \\
\hline
\end{tabular}

Na etapa I dosaram-se cinco famílias de misturas: uma de referência, com $100 \%$ de $\mathrm{CP}$, duas com $15 \%$ e $25 \%$ de CCAM e de CCAN, com substituição de cimento em massa, nas relações água-materiais cimentícios (a/cm) 0,45, 0,55 e 0,65 . Os abatimentos foram fixados em $80 \pm 20$ $\mathrm{mm}$, com uso de aditivo superplastificante à base de policarboxilatos no teor necessário. Os ensaios de resistência à compressão axial foram realizados com corpos de prova cilíndricos de $10 \mathrm{~cm}$ x $20 \mathrm{~cm}$, conforme a NBR 5738 (ABNT, 2003a) e a NBR 5739 (ABNT, 2003b), a 28 e 91 dias de idade. Mais detalhes sobre a caracterização dos materiais e metodologia experimental dos ensaios iniciais, como ordem de colocação dos materiais na betoneira e tempos de mistura, estão em Isaia et al. (2010).

\section{Métodos de ensaios para a durabilidade}

Os ensaios de durabilidade foram realizados segundo os métodos a seguir:

(a) carbonatação acelerada: c.p. cilíndricos de 10x20 cm curados por 7 dias em câmara úmida, serrados em três partes de $6,5 \times 10 \mathrm{~cm}$, uma delas utilizada para o pré-condicionamento conforme TC116-PCD (RILEM, 1999), para redistribuição uniforme da umidade interna. Foram ensaiados em câmara com controle de temperatura $(23 \pm 1){ }^{\circ} \mathrm{C}$, umidade de $(75 \pm 2) \%$, teor de $\mathrm{CO}_{2}$ de $(5 \pm 0,2) \%$, com tempo de residência de 3, 6, 9 e 12 semanas. Após cada idade romperam-se os c.p. por compressão diametral e aspersão das faces com fenolftaleína (RILEM, 1988), medidas as profundidades carbonatadas por digitalização de imagens, calculadas as profundidades médias com as quais foram determinados os coeficientes de carbonatação acelerada $\mathrm{k}_{\mathrm{ac}}$ em mm.semana ${ }^{-0,5}$, por meio de regressão linear; (b) carbonatação natural: vigotas prismáticas de 20x20x70 cm curadas por 7 dias em câmara úmida e após em ambiente abrigado, com testemunhos cilíndricos 10x20 cm extraídos às idades 1,5, 2,0 e 2,5 anos (900 dias), cortados em 2 partes de $10 \mathrm{x}$ $10 \mathrm{~cm}$, rompidos por compressão diametral e as faces aspergidas com fenolftaleína. As profundidades carbonatadas foram calculadas do mesmo modo de carbonatação acelerada e, após, os coeficientes de carbonatação natural $\mathrm{k}_{\text {nat }} \mathrm{em}$ $\mathrm{mm} . \mathrm{ano}^{-0,5}$, por meio de regressão linear;

(c) penetração de cloretos por imersão (EPCI): c.p. cilíndricos de $10 \times 20 \mathrm{~cm}$ curados por 7 dias em câmara úmida, serrados para 10x10 cm, com as faces transversais impermeabilizadas e imersos em tanque com solução de $\mathrm{NaCl}$, com concentração de $\mathrm{Cl}^{-}$semelhante à da água do $\operatorname{mar}(20.000 \mathrm{mg} / \mathrm{l})$ conforme Mehta e Monteiro (2008). Nas idades de ensaio, 1, 7, 14, 28, 56 e 91 dias, foram rompidos por compressão diametral e aspergidos com solução de $\mathrm{AgNO}_{3}$ para medida da profundidade dos íons $\mathrm{Cl}^{-}$, de modo similar à carbonatação acelerada. Por regressão linear foram calculados os coeficientes de penetração de $\mathrm{Cl}^{-}$em mm.semana 0,5 ;

(d) resistência à penetração dos íons cloretos: conforme a ASTM C1202 ( AMERICAN..., 2006a), os c.p. cilíndricos de 10x20 cm foram curados em câmara úmida por 7 dias, serrados para $9,5 \times 5 \mathrm{~cm}$, saturados e colocados em células de acrílico com solução de $3 \%$ de $\mathrm{NaCl}$ numa e $0,3 \mathrm{~N}$ de $\mathrm{NaOH}$ noutra. A 91 dias de idade mediu-se a penetração de $\mathrm{Cl}^{-}$pela corrente elétrica para diferença de potencial de $60 \mathrm{~V}$, durante $6 \mathrm{~h}$, e o somatório do produto ampère $\mathrm{x}$ tempo forneceu a carga elétrica passante, em coulomb. Esse ensaio foi repetido para testemunhos de $10 \times 20 \mathrm{~cm}$

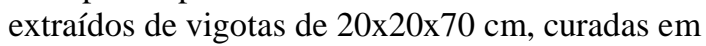
ambiente externo por 540 dias;

(e) resistividade elétrica aparente - método de Wenner (4 eletrodos): conforme a ASTM G57 
(AMERICAN..., 2012) moldaram-se c.p. prismáticos de 10x10x17 cm curados em câmara úmida por 91 dias, ensaiados nas idades $3,7,14$, 28, 56, 91 e 182 dias, em circuito elétrico conforme descrito na norma. Calculou-se a resistividade elétrica $(\rho)$ conforme a NBR 7117 (ABNT, 2012), em $\Omega . c m$;

(f) condutividade elétrica específica da solução dos poros: Conforme Shi, Stegemann e Caldwall (1998), moldaram-se c.p. cilíndricos de pasta de $4 \times 8 \mathrm{~cm}$, curados em câmara úmida por 91 dias. Depois, após 3, 7, 14, 28, 56, 91 e 182 dias, determinaram-se as concentrações de $\mathrm{Na}^{+}, \mathrm{K}^{+}$, $\mathrm{Ca}^{2+}, \mathrm{OH}^{-}$e $\mathrm{SO}_{4}{ }^{2-}$ pelas equações propostas pelo autor e as condutividades elétricas $\Omega^{-1}$, calculadas a partir dessas concentrações;

(g) permeabilidade do concreto ao oxigênio: conforme Kollek (1989) e Cembureau Recommendation, em c.p. cilíndricos de $15 \times 30$ $\mathrm{cm}$, curados em câmara úmida por 28 dias, serrados para $5 \times 15 \mathrm{~cm}$ e pré-condicionados segundo a TC116-PCD (RILEM, 1999) para equalização da umidade interna, selados no perímetro lateral e ensaiados em células de pressão a 91 e 360 dias. Calculou-se o coeficiente de permeabilidade, em $\mathrm{m}^{2}$, pela equação de HagenPoiseuille para fluido compressível com fluxo laminar para corpos porosos com pequena capilaridade, sob condições uniformes;

(h) Absorção capilar de água: conforme a TC116-PCD (RILEM, 1999), em c.p. cilíndricos de $10 \times 20 \mathrm{~cm}$, curados em câmara úmida por 28 dias, serrados para $5 \times 10 \mathrm{~cm}$ e pré-condicionados, selados no perímetro lateral e depois imersos em água nas idades 91 e 360 dias. A água de absorção foi registrada para cada intervalo de tempo entre $10 \mathrm{~min}$ e $24 \mathrm{~h}$, expressa por unidade de área da superfície de ensaio $\left(\mathrm{g} / \mathrm{m}^{2}\right)$;

(i) resistência química a ácidos: conforme ASTM C267 (AMERICAN..., 2006b) e metodologia de Mehta e Folliard (1995), com c.p. cilíndricos de $5 \times 10 \mathrm{~cm}$ de argamassa, curados em tanques por 7 dias em água e cal dentro de câmara úmida. Após, foram pesados e submersos em tanque com $\mathrm{HCl}$ a $1 \%$, e as leituras semanais das massas realizadas até a idade de 84 dias. As perdas de massa, em \%, foram calculadas entre as massas iniciais e a cada idade de ensaio;

(j) resistência à ação de solução de sulfatos: conforme a ASTM C1012 (AMERICAN..., 2012), em c.p. prismáticos de argamassa de $25 \times 25 \times 285$ mm curados em água e cal por 28 dias dentro de câmara úmida. Após foram medidos e colocados em tanque com $\mathrm{Na}_{2} \mathrm{SO}_{4}$ a $5 \%$, e a cada semana retirados para medidas longitudinais até 26 semanas. As variações dimensionais foram calculadas em porcentagem, relacionadas com a medida inicial; e

(k) reatividade álcali-sílica: conforme a norma NBR 15877-1 (ABNT, 2008a), em c.p. prismáticos de $25 \times 25 \times 285 \mathrm{~mm}$ em argamassa (ABNT, 2010) e NBR 15577-5 (ABNT, 2005b)) moldados com cimento padrão e/ou composto, mantidos $24 \mathrm{~h} \mathrm{em}$ câmara úmida e após em banho a $80^{\circ} \mathrm{C}$ por $24 \mathrm{~h}$ com solução de $\mathrm{NaOH} 1 \mathrm{~N}$, com leituras $\mathrm{L}_{0}$ e mais 3 entre 16 e 30 dias. Para concreto, moldaram-se c.p. prismáticos de 100x100x285 mm (NBR 15577-6 (ABNT, 2008c)), com cimento padrão, CPIIF e CPIIZ com misturas de CCAM e CCAN no teor de $15 \%$, mantidos 24 h em câmara úmida $\left(\mathrm{L}_{0}\right)$ e após em banho a $38{ }^{\circ} \mathrm{C}$ com leituras a 7, 28, 56 dias e mensais até 2 anos. Calcularam-se os resultados, em porcentagem, entre as leituras iniciais e em cada uma das idades intermediárias.

\section{Análise e discussão dos resultados}

\section{Resistência à compressão axial: etapas I e II}

A Figura 1 apresenta as resistências à compressão a 28 e 91 dias e evidencia os traços CCAM15 com resistências mais elevadas, ou similares, para ambas as idades, mostrando que a moagem prévia foi benéfica para o aumento da resistência à compressão em relação ao REF, provavelmente pela menor dimensão das partículas que aumentam o potencial zeta superficial; logo a nucleação para formação de novos locais para reações as químicas, em relação à cinza natural. Ainda, outra causa possível para essas resistências mais altas seria a ação física das partículas mais finas da cinza moída que atuariam por obstrução de vazios capilares, tornando a pasta cimentícia mais compacta. Esse mesmo comportamento não aconteceu com os traços CCAN15, que mostraram menor resistência a 28 dias que REF, nas relações $\mathrm{a} / \mathrm{mc} 0,45$ e 0,55 , possivelmente por causa das partículas maiores do que a cinza moída, aproximadamente com o dobro da dimensão média da CCAM, conforme a Tabela 1 .

A 91 dias, o avanço das reações pozolânicas possibilitaram ao traço N15 crescimento de resistência em patamar similar ao CCAM, superando REF em até $18 \%$, em média. A partir de $\mathrm{a} / \mathrm{mc}=0,55$ a inflexão de N15 foi mais pronunciada, mostrando que, para menores a/mc, foi maior o efeito positivo da CCAN, que praticamente se igualou em resistência aos traços CCAM para a relação $\mathrm{a} / \mathrm{mc}=0,45$. O aumento de idade de 28 para 91 dias foi benéfico para N15, com $\mathrm{f}_{\mathrm{c} 91}$ iguais ou maiores que os $\mathrm{REF}_{91}$. 
A Tabela 3 apresenta as relações a/mc para $\mathrm{f}_{\mathrm{c} 28} 25$, 30 e $40 \mathrm{MPa}$, resistências de dosagem usualmente utilizadas em estruturas correntes de edificações usuais. Realizaram-se regressões exponenciais, segundo a equação de Abrams, entre $\mathrm{f}_{\mathrm{c} 28} \mathrm{e}$ as respectivas relações a/mc $\mathrm{mc}_{28}$ da Figura $1\left(\mathrm{r}^{2} \geq 0,9\right)$, entrando-se nessas equações com os valores de $\mathrm{f}_{\mathrm{c} 28}$ 25, 30 e $40 \mathrm{MPa}$ e obtendo-se as relações a/mc da Tabela 3. As mesmas regressões foram realizadas com os resultados das resistências $\mathrm{f}_{\mathrm{c} 91}$ versus relações $\mathrm{a} / \mathrm{mc}_{91}$ também da Figura $1\left(\mathrm{r}^{2} \geq 0,9\right)$. Entrou-se nessas equações com os respectivos $\mathrm{a} / \mathrm{mc}_{28}$ para obtenção das resistências $\mathrm{fc}_{91}$ para cada classe de concreto. Foram empregadas as resistências $\mathrm{fc}_{91}$ porque a maioria das variáveis da durabilidade foi determinada a 91 dias ou em idades mais elevadas, visando-se a maior coerência nas regressões realizadas com as variáveis de estudo, quando os resultados foram analisados em igualdade de resistência à compressão axial.

Para cada classe de resistência do concreto a 28 dias (terceira linha na Tabela 3), para melhor compreensão relativa entre as resistências a 91 dias, calcularam-se índices tendo como base $\mathrm{I}_{\mathrm{REF91}}$ $=100$, sendo as demais classes proporcionais a ele. Para a classe $25 \mathrm{MPa}$ os índices de resistência $\mathrm{f}_{\mathrm{c} 91}$ foram $15 \%$ (115) e 11\% (111) mais elevados do que o REF.

\section{Ensaios de durabilidade}

Realizaram-se os ensaios de durabilidade a 91 dias de idade, a não ser quando informada outra idade. Realizou-se análise de regressão entre as resistências à compressão a 91 dias (Figura 1), e os valores de cada variável da durabilidade segundo métodos listados no plano da pesquisa. Resultaram para $\mathrm{f}_{\mathrm{c} 28}=25,30$ e $40 \mathrm{MPa}$ as relações a/mc $\mathrm{mc}_{28}=$ $0,63,0,56$ e 0,46 respectivamente, constantes na Tabela 3, para as quais foram calculados os valores dos ensaios de durabilidade, exceto RAS, para os três níveis de resistência preestabelecidos. Foram testados quatro modelos de regressão: linear, logarítmico, exponencial e potência, escolhendo-se o que forneceu o melhor ajuste, $r^{2} \geq 0,90$, ou seja, quando mais de $90 \%$ da variância total da variável da durabilidade (dependente) foi explicada pela variância da resistência $\mathrm{fc}_{91}$ (variável independente).

\section{Carbonatação}

A Tabela 4 e a Figura 2 mostram os coeficientes de carbonatação acelerada, após 91 dias de idade, em $\mathrm{mm} . \mathrm{sem}^{-0,5}$ e natural, após 900 dias $(2,5$ anos $)$ em mm.ano ${ }^{-0,5}$, esta última em cura abrigada laboratorial, com seus respectivos índices em relação ao $\mathrm{REF}=100$.

Os traços REF apresentaram os menores coeficientes por conter maiores teores de $\mathrm{CH}$, os quais foram parcialmente consumidos pela sílica amorfa dos traços com CCA. Em negrito, itálico e sublinhado estão os menores índices encontrados para cada tipo de mistura (sombreados para as misturas de referência $=100$ e para as de CCA calculados proporcionalmente em relação à REF, $\mathrm{I}=120$ para CCAM15 e $\mathrm{I}=114$ para CCAN15), observando-se para os traços CCAN15 menores coeficientes que os CCAM15, com exceção do $\mathrm{f}_{\mathrm{c} 28 \text { - }}$ $25 \mathrm{MPa}$

O Quadro 2 apresenta os resultados originais da resistência à compressão axial e suas respectivas relações a/mc, para a idade de 91 dias, para as três misturas estudadas, e o Quadro 3 mostra os teores de hidróxido de cálcio remanescentes encontrados também para a idade de 91 dias nos ensaios acelerados, por meio de análise química analítica, para os três níveis de resistências $\mathrm{f}_{\mathrm{c} 28}=25,30$, e 40 $\mathrm{MPa}$.

Figura 1 - Resistência à compressão axial a 28 e 91 dias obtida com os traços da Tabela 2

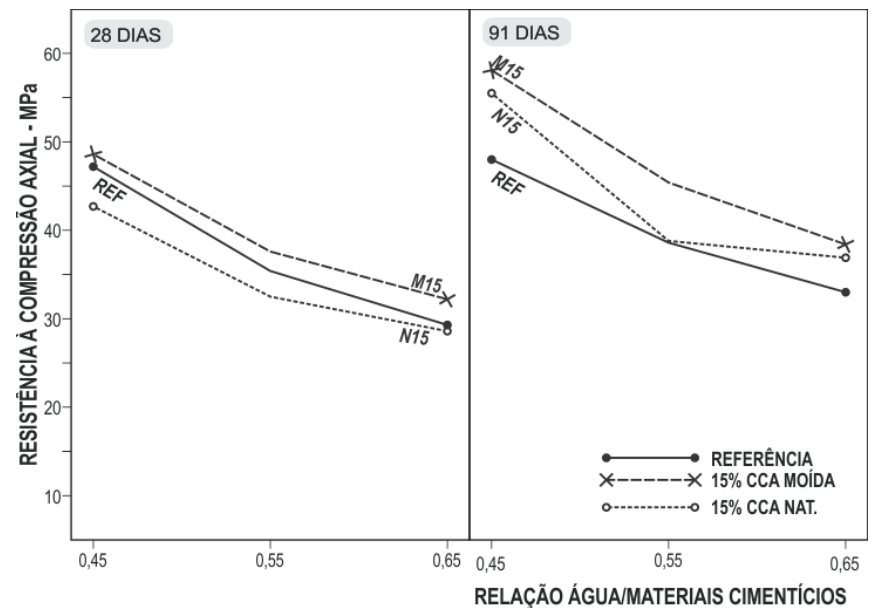


Tabela 3 - Relações a/mc e resistências à compressão a 91 dias, em igualdade de $\mathrm{f}_{\mathrm{c} 28}=25,30$ e $40 \mathrm{MPa}$, calculados a partir dos traços da Tabela 2 (Figura 1)

\begin{tabular}{|c|c|c|c|c|}
\hline $\begin{array}{c}\mathbf{f}_{\mathbf{c 2 8}} \\
\mathbf{M P a}\end{array}$ & $\begin{array}{c}\text { Parâmetros de } \\
\text { análise }\end{array}$ & REF & $\begin{array}{l}\text { CCA } \\
\text { M15 }\end{array}$ & $\begin{array}{l}\text { CCA } \\
\text { N15 }\end{array}$ \\
\hline 25 & $\begin{array}{l}\text { Relação } a / m_{28} \\
f_{c 91}\left(p / f_{c 28}=25 \mathrm{MPa}\right) \\
\text { Indice }_{91}(\mathrm{REF}=100)\end{array}$ & $\begin{array}{r}0,63 \\
28,9 \\
100\end{array}$ & $\begin{array}{r}0,65^{1} \\
33,1 \\
115\end{array}$ & $\begin{array}{r}0,61 \\
32,1 \\
111 \\
\end{array}$ \\
\hline 30 & $\begin{array}{l}\text { Relação } \mathrm{a} / \mathrm{mc}_{28} \\
\mathrm{f}_{\mathrm{c} 91}\left(\mathrm{p} / \mathrm{f}_{\mathrm{c} 28}=30 \mathrm{MPa}\right) \\
\text { Indice }_{91}(\mathrm{REF}=100)\end{array}$ & $\begin{array}{r}0,56 \\
33,2 \\
100\end{array}$ & $\begin{array}{r}0,60 \\
36,8 \\
111\end{array}$ & $\begin{array}{r}0,53 \\
39,3 \\
118 \\
\end{array}$ \\
\hline 40 & $\begin{array}{l}\text { Relação } \mathrm{a} / \mathrm{mc}_{28} \\
\mathrm{f}_{\mathrm{c} 91}\left(\mathrm{p} / \mathrm{f}_{\mathrm{c} 28}=40 \mathrm{MPa}\right) \\
\text { Indice }_{91}(\mathrm{REF}=100)\end{array}$ & $\begin{array}{r}0,46 \\
41,8 \\
100\end{array}$ & $\begin{array}{r}0,48 \\
48,6 \\
116\end{array}$ & $\begin{array}{r}0,42 \\
55,1 \\
133\end{array}$ \\
\hline
\end{tabular}

Nota: ${ }^{1}$ Adotou-se o valor mínimo da NBR 12655 (ABNT, 2006) para a classe I: a/mc $\leq 0,65 ;$ e $^{2}$ Esses valores extrapolaram as faixas de estudo das curvas de Abrams adotadas.

Tabela 4 - Coeficientes de carbonatação acelerada e natural (REF: I=100)

\begin{tabular}{c|c|c|c|c}
\hline & $\begin{array}{c}\mathbf{f}_{\mathbf{c 2 8}} \\
\mathbf{M P a}\end{array}$ & $\mathbf{R E F}$ & $\begin{array}{c}\text { CCAM } \\
\mathbf{1 5}\end{array}$ & $\begin{array}{c}\mathbf{C C A N} \\
\mathbf{1 5}\end{array}$ \\
\hline $\mathrm{k}_{\mathrm{c}}$ acelerado & 25 & $3,24-\underline{\mathbf{1 0 0}}$ & $3,89-120$ & $3,68-114$ \\
mm. sem $^{-0,5}$ & 30 & $2,63-\underline{\mathbf{1 0 0}}$ & $3,44-131$ & $2,91-111$ \\
após 91 dias $^{*}$ & 40 & $1,80-\underline{\mathbf{1 0 0}}$ & $2,27-125$ & $1,95-105$ \\
\hline $\mathrm{k}_{\mathrm{c}}$ natural & 25 & $4,12-\underline{\mathbf{1 0 0}}$ & $4,97-121$ & $5,22-127$ \\
mm.ano $^{-0,5}$ & 30 & $3,62-\underline{\mathbf{1 0 0}}$ & $4,59-127$ & $4,36-120$ \\
900 dias & 40 & $2,62-\underline{\mathbf{1 0 0}}$ & $3,37-129$ & $3,22-123$ \\
\hline
\end{tabular}

Nota: *idade em que foram colocados na câmara; e ** 2,5 anos.

Figura 2 - Variação do coeficiente carbonatação acelerada e natural com a resistência à compressão $f_{c 28}$

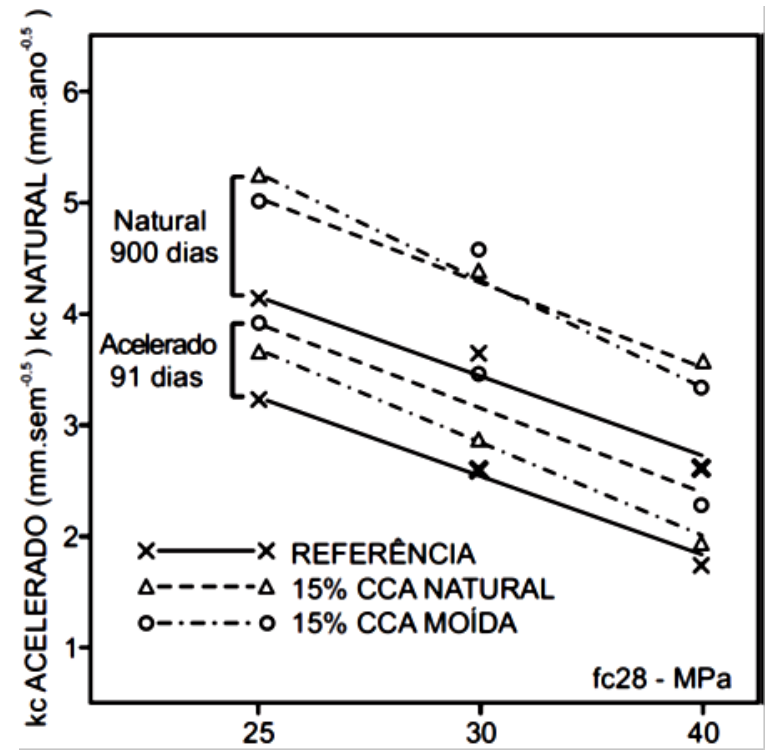

Quadro 2 - Resistências à compressão a 91 dias, em $\mathrm{MPa}$, e respectivas relações a/mc e índices

\begin{tabular}{|c|c|c|c|}
\hline a/mc & REF & $\begin{array}{c}\text { CCAM } \\
\mathbf{1 5}\end{array}$ & $\begin{array}{c}\text { CCAN } \\
\mathbf{1 5}\end{array}$ \\
\hline 0,45 & $43,0-100$ & $53,1-\underline{\mathbf{1 2 3}}$ & $50,5-117$ \\
0,55 & $33,6-100$ & $40,4-\underline{\mathbf{1 2 0}}$ & $33,8-101$ \\
0,65 & $28,0-100$ & $33,4-\underline{\mathbf{1 1 9}}$ & $31,9-114$ \\
\hline
\end{tabular}

240 Isaia, G. C.; Zerbino, R. L.; Gastaldini, A. L. G.; Sensale, G. R. 
Quadro 3 - Teores de $\mathrm{CH}$ remanescentes, em \%, e respectivos índices para 91 dias de idade

\begin{tabular}{|c|c|c|c|}
\hline $\begin{array}{c}\mathbf{f}_{\mathbf{c 2 8}} \\
\mathbf{M P a}\end{array}$ & $\mathbf{R E F}$ & $\begin{array}{c}\text { CCAM } \\
\mathbf{1 5}\end{array}$ & $\begin{array}{c}\text { CCAN } \\
\mathbf{1 5}\end{array}$ \\
\hline 25 & $2,95-100$ & $2,59-88$ & $1,45-49$ \\
30 & $3,40-100$ & $3,21-94$ & $2,34-69$ \\
40 & $3,62-100$ & $3,40-94$ & $3,11-86$ \\
\hline
\end{tabular}

Observa-se no Quadro 2 que, em igualdade de relação a/mc e, logo, de consumo de materiais cimentícios, as resistências à compressão $\mathrm{f}_{\mathrm{c} 91}$ para as misturas CCAN15 foram inferiores às CCAM15 em vista da menor atividade pozolânica das primeiras, conforme consta no Quadro 1. A Tabela 3 mostra que, para a obtenção dos níveis de resistência a 28 dias de 25,30 e $40 \mathrm{MPa}$, as relações $\mathrm{a} / \mathrm{mc}_{28}$ para os traços CCAN15 foram $0,61,0,53$ e 0,42 respectivamente, valores inferiores às relações $\mathrm{a} / \mathrm{mc}_{28}$ para CCAM15, ou seja, devido às reatividades químicas mais baixas $\mathrm{e}$ porosidades mais altas das cinzas naturais, tiveram de ter majorados os consumos de cimento e diminuídas as relações a/mc para atingir o mesmo patamar de resistência das cinzas moídas.

Sabe-se que, à medida que as relações a/mc decrescem, diminuem o teor e as dimensões dos poros e, por consequência, os espaços disponíveis para a formação de cristais de grande tamanho como os do hidróxido de cálcio em relação aos de C-S-H. O Quadro 3 ilustra esse comportamento em que as misturas CCAN15 tiveram menor teor de $\mathrm{CH}$ remanescentes do que as CCAM15, provavelmente por causa das menores relações a/mc, atividade pozolânica mais baixa e, também, pelo menor teor de hidratação, porque as resistências à compressão, em igualdade de relação $\mathrm{a} / \mathrm{mc}$ foram inferiores às da cinza moída. Os traços com CCAM15 apresentaram relações a/mc maiores como também coeficientes de carbonatação acelerada $\left(\mathrm{k}_{\mathrm{cACEL}}\right)$ a 91 dias mais elevados (Tabela 4) em relação às misturas CCAN15, e ainda maiores do que REF devido à menor reserva alcalina propiciada pelo consumo de $\mathrm{CH}$ pelas reações pozolânicas, o que está de acordo com o conhecimento atual. Aparentemente, os concretos CCAN15 deveriam apresentar coeficientes de carbonatação mais elevados do que CCAM15, devido a sua menor atividade pozolânica e menor resistência à compressão em igualdade de relação a/mc (Quadro 2). Esses últimos, entretanto, em igualdade de resistência, apresentaram maior relação a/mc, reserva alcalina mais alta e, também, maior $\mathrm{k}_{\mathrm{cACEL}}$ a 91 dias do que os concretos com cinza natural. É difícil concluirse o que predomina entre essas duas análises, em igualdade de relação $\mathrm{a} / \mathrm{mc}$ e de resistência à compressão, porque a velocidade de carbonatação, em princípio, é governada pela razão inversa do tempo em que a reserva alcalina é consumida, isto é, tanto maior quanto menor é o tempo em que o teor de $\mathrm{CH}$ é suprimido. Presume-se que na comparação entre os resultados de carbonatação das duas CCA, natural e moída, os vazios internos da primeira teriam tido influência predominante sobre o comportamento à carbonatação acelerada.

Assim, a causa mais provável do melhor desempenho de CCAN15, em igualdade de resistência à compressão, seriam os poros internos dos grãos incompletamente moídos, com acúmulo de água adsorvida interna, que dificultariam a difusão do $\mathrm{CO}_{2}$. As diferenças entre os índices de CCAM e CCAN são maiores para o ensaio acelerado com $5 \%$ de $\mathrm{CO}_{2}$ (média $15,3 \%$ ) do que o ensaio natural (média 6,5\%).

Os números da Tabela 4 mostram que a CCAN é mais sensível ao ensaio acelerado do que o natural. Os valores de carbonatação acelerada $\left(\mathrm{k}_{\mathrm{cACEL}} \mathrm{em}\right.$ $\mathrm{mm} \cdot \mathrm{sem}^{-0,5}$ ) foram mais baixos que os de carbonatação natural $\left(\mathrm{k}_{\mathrm{cNAT}}\right.$ em mm.ano $\left.{ }^{-0,5}\right)$, cuja relação $\mathrm{k}_{\mathrm{cACEL}} / \mathrm{k}_{\mathrm{cNAT}}$ foi em média 0,74 para REF e CCAM e 0,66 para CCAN, cujo coeficiente de variação foi ao redor de $6 \%$. A hipótese realizada no parágrafo anterior sobre o maior conteúdo de umidade dentro dos poros da CCAN é coerente com esses resultados porque, em longo prazo, com o aumento do tempo de cura em ambiente abrigado, o teor de água no interior dos poros tende a diminuir, o que aumentaria a difusão do $\mathrm{CO}_{2}$ nas misturas com CCAN e, logo, a velocidade de carbonatação. Esses resultados também estão coerentes com os obtidos por Isaia et al. (2001), que observaram a mesma tendência para teores de adições minerais em concreto $\leq 25 \%$. Essas relações dependem do tipo e teor de pozolana contidas no concreto, de sua reatividade química e, principalmente, da idade de ensaio do concreto em carbonatação natural, que tende para dado valorlimite.

\section{Coeficientes de penetração acelerada e migração iônica (ASTM C1202) de cloretos}

A Tabela 5 e a Figura 3 mostram os resultados dos coeficientes de penetração acelerada de $\mathrm{Cl}^{-}$por imersão, medidas por $\mathrm{AgNO}_{3}$ das profundidades de penetração até 91 dias, e as cargas passantes, 
em coulomb, da resistência à penetração iônica $\begin{array}{llll}\text { (migração) segundo a } & \text { ASTM } & \text { C1202 }\end{array}$ (AMERICAN..., 2006a) a 91 dias em c.p. cilíndricos moldados, e a 540 dias em testemunhos extraídos de vigotas de $25 \times 25 \times 75 \mathrm{~cm}$ curadas em ambiente externo desabrigado.

A migração iônica, Figura 3a, é governada pela diferença de potencial aplicada entre os c.p., e a passagem da corrente depende da continuidade dos poros do concreto e da condutividade elétrica da solução iônica dos poros. Observa-se que as misturas CCAM15 e CCAN15 apresentaram penetração iônica na ordem inversa a suas atividades pozolânicas, conforme o Quadro 1, ou seja, as cinzas moídas mostraram maior refinamento dos poros do que as naturais, o que ocasionou maior oposição à passagem dos íons para a primeira em relação à segunda. A família CCAN15 ficou classificada, segundo a ASTM C1202 (AMERICAN..., 2006a), como de penetração iônica moderada a 91 dias e baixa a 540 dias, enquanto a CCAM15 como baixa a 91 dias e muito baixa a 540 dias. Em relação à REF houve queda, em coulomb, de cerca de $40 \%$ para 91 dias e de $70 \%$ a 540 dias para CCAM15, e respectivamente de $28 \%$ e de $41 \%$ para a CCAN15, segundo a Tabela 5.

Observa-se na Figura $3 b$ que houve alternância entre os coeficientes de penetração de cloretos entre as resistências à compressão de $25 \mathrm{MPa}$ e 40 $\mathrm{MPa}$, com maiores resultados para a primeira nos traços com CCAN15 e menores para a segunda nos traços CCAM15. Para a resistência de $30 \mathrm{MPa}$ os resultados equivaleram-se. De certa forma repetiuse o comportamento da carbonatação natural da Tabela 3 em relação a CCAM15, ao menos para 40 $\mathrm{MPa}$, apesar de as diferenças entre ambos, para este caso, terem sido mais altas, cerca de $12 \%$. As similaridades de comportamento entre penetração iônica de Cl, segundo a ASTM C1202 (AMERICAN..., 2006a), e os coeficientes de penetração de cloretos estão relacionadas com os mecanismos de transporte por difusão que governam este último processo, e o primeiro é ocasionado pela diferença de potencial entre as duas células com soluções de $0,3 \mathrm{M}$ de $\mathrm{NaOH}$ e $3 \%$ de $\mathrm{NaCl}$, que dependem da continuidade dos poros que, no caso da CCAN, é cortada pelos vazios internos dos grãos mais porosos. À medida que a resistência aumenta, a superfície interna dos vazios desses grãos maiores contribuiria com superfícies mais amplas para fixação dos cloretos em relação à CCA moída, que apresenta grãos de menores dimensões e, logo, com menor superfície interna que as anteriores.

\section{Resistividade e condutividade elétricas}

A Tabela 6 e a Figura 4 apresentam os resultados dos ensaios da resistividade elétrica aparente (4 eletrodos, método de Wenner) e a condutividade elétrica específica da solução dos poros do concreto, segundo Shi, Stegemann e Caldwall (1998). O ensaio de resistividade elétrica aparente é regido pelo mecanismo de transporte por migração iônica, logo a compacidade da microestrutura da pasta é a principal causa da obstrução à passagem da corrente elétrica. As famílias de traços CCAM15 foram as que apresentaram as maiores resistividades elétricas devido ao refinamento das dimensões dos poros, resultado de sua maior atividade pozolânica (Quadro 1). Segundo a ACI 222R (AMERICAN..., 2011), os concretos que apresentam resistividade elétrica superior a $200 \Omega$.cm são considerados como de baixa taxa de corrosão, logo todos os traços da Tabela 5 enquadram-se dentro dessa categoria. Entretanto, os traços com CCAN foram os que apresentaram as menores resistividades elétricas, inclusive em relação ao REF, revelando menor obstrução à corrente elétrica e, logo, o menor desempenho nessa variável da durabilidade em relação às demais misturas. Comparando-se os resultados de migração iônica em que é imposta entre os eletrodos a diferença de potencial de $60 \mathrm{~V}$ medindo-se a corrente passante durante $6 \mathrm{~h}$, os de resistividade elétrica consistem do posicionamento de quatro eletrodos, alinhados e equidistantes um do outro, na superfície do concreto, aplicando-se uma corrente elétrica entre os dois eletrodos externos, sendo medida a diferença de potencial estabelecida entre os dois eletrodos internos. Tratase, portanto, de um ensaio de migração com baixa diferença de potencial, de apenas $5 \mathrm{~V}$ entre os eletrodos e de rápida medição, diferenciando-se do anterior em termos do fluxo de corrente passante e de tempo, o que explicaria os resultados opostos obtidos para as misturas CCAN15 e CCAM15 entre essas duas propriedades, apesar de ambas se basearem na passagem da corrente elétrica pelos corpos de prova. Trata-se, portanto, de procedimentos metodológicos distintos e de uso de equações específicas para cada método, que não se baseiam nos mesmos procedimentos de cálculo, razão pela qual os resultados não são comparáveis entre si. 
Tabela 5 - Coeficientes de penetração acelerada de $\mathrm{Cl}^{-}$a 91 dias e migração iônica a 91 e 540 dias (REF: I = 100)

\begin{tabular}{c|c|c|c|c}
\hline & $\begin{array}{c}\mathbf{f}_{\mathbf{c 2 8}} \\
\mathbf{M P a}\end{array}$ & $\mathbf{R E F}$ & $\begin{array}{c}\text { CCA } \\
\mathbf{M 1 5}\end{array}$ & $\begin{array}{c}\text { CCA } \\
\mathbf{N 1 5}\end{array}$ \\
\hline $\mathrm{k}_{\mathrm{cl}}{ }^{-}$cloretos & 25 & $9,96-100$ & $8,09-\mathbf{8 1}$ & $9,26-93$ \\
mm.sem. $^{-0,5}$ & 30 & $9,35-100$ & $7,67-82$ & $7,55-\mathbf{8 1}$ \\
91 dias & 40 & $8,33-100$ & $6,31-76$ & $5,37-\underline{\mathbf{6 4}}$ \\
\hline Migração iônica & 25 & $3743-100$ & $2277-\underline{\mathbf{6 1}}$ & $2667-71$ \\
Coulomb & 30 & $3444-100$ & $2113-\underline{\mathbf{6 1}}$ & $2458-71$ \\
91 dias & 40 & $2947-100$ & $1737-\underline{\mathbf{5 9}}$ & $2149-73$ \\
\hline Migração iônica & 25 & $2851-100$ & $804-\underline{\mathbf{2 8}}$ & $1690-59$ \\
Coulomb & 30 & $2623-100$ & $782-\underline{\mathbf{3 0}}$ & $1550-59$ \\
540 dias & 40 & $2286-100$ & $747-\mathbf{3 3}$ & $1357-59$ \\
\hline
\end{tabular}

Figura 3 - (a) Variação da penetração iônica a 91 e 540 dias, com a resistência à compressão $f_{c 28}$ e (b) variação do coeficiente de penetração acelerada de cloretos por imersão a 91 dias com a resistência $f_{c 28}$

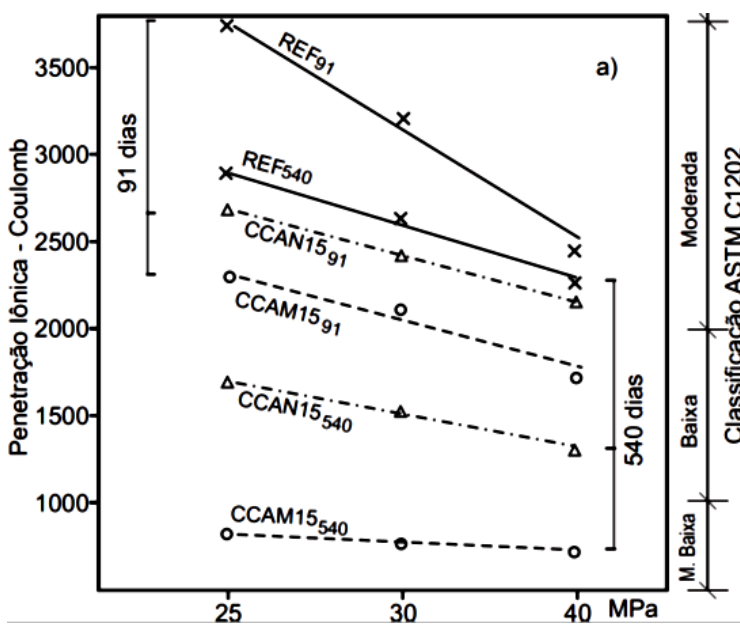

(a) Variação da penetração iônica a 91 e 540 dias, com a resistência à compressão $\mathrm{f}_{\mathrm{c} 28}$

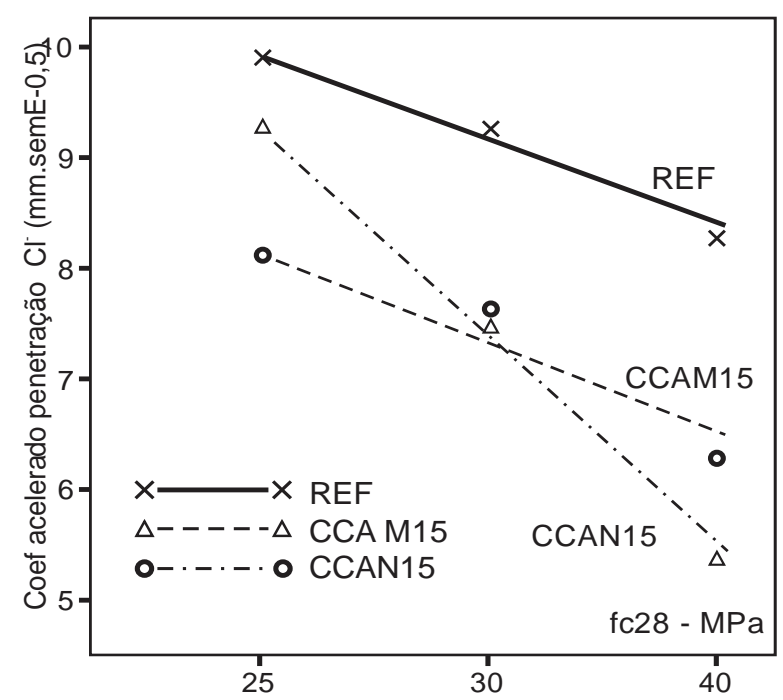

(b) Variação do coeficiente de penetração acelerada de cloretos por imersão a 91 dias com a resistência $\mathrm{f}_{\mathrm{c} 28}$

Tabela 6 - Resistividade elétrica aparente a 91 dias e condutividade elétrica específica a 182 dias (REF: $I=100)$

\begin{tabular}{|c|c|c|c|c|}
\hline & $\begin{array}{c}\mathbf{f}_{\mathbf{c 2 8}} \\
\mathbf{M P a}\end{array}$ & REF & $\begin{array}{l}\text { CCA } \\
\text { M15 }\end{array}$ & $\begin{array}{c}\text { CCA } \\
\text { N15 }\end{array}$ \\
\hline $\begin{array}{c}\text { Res. elétr. } \\
\text { Apar. } \\
91 \text { dias } \Omega . c m\end{array}$ & $\begin{array}{l}25 \\
30 \\
40\end{array}$ & $\begin{array}{l}420-100 \\
450-100 \\
480-100\end{array}$ & $\begin{array}{l}590-\underline{140} \\
710-\underline{159} \\
910-\underline{189}\end{array}$ & $\begin{array}{l}370-87 \\
380-86 \\
410-85\end{array}$ \\
\hline $\begin{array}{l}\text { Cond. elétr. } \\
\text { espec. } \\
182 \text { d. } \Omega^{-1}\end{array}$ & $\begin{array}{l}25 \\
30 \\
40\end{array}$ & $\begin{array}{l}0,55-100 \\
0,58-100 \\
0,63-100\end{array}$ & $\begin{array}{l}0,43-\underline{77} \\
0,45-\underline{78} \\
0,53-\underline{84}\end{array}$ & $\begin{array}{l}0,49-88 \\
0,52-89 \\
0,56-89\end{array}$ \\
\hline
\end{tabular}


Figura 4 - Resistividade elétrica aparente a 91 dias e condutividade elétrica específica a 182 dias $\times \mathrm{f}_{\mathrm{c} 28}$

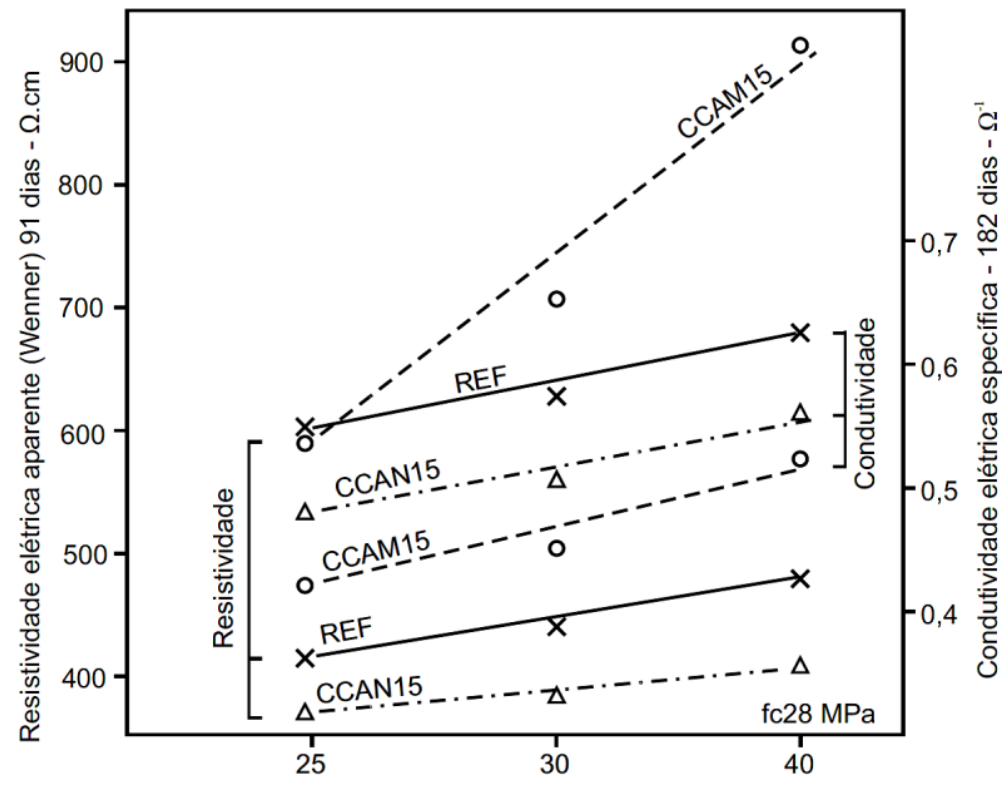

A condutividade elétrica específica, segundo Shi, Stegemann e Caldwell (1998), é um cálculo indireto da condução da corrente elétrica pelos íons $\mathrm{Na}^{+}, \mathrm{K}^{+}, \mathrm{Ca}^{2+}, \mathrm{OH}^{-}$e $\mathrm{SO}_{4}{ }^{2-}$ da solução dos poros. É um mecanismo recíproco da resistividade elétrica, sendo, portanto, comandado pelos mesmos fatores antes enumerados. A família CCAM15 apresentou menores condutividades elétricas, cerca de $20 \%$ inferiores ao REF, enquanto as CCAN15 ao redor de $11 \%$ menores, e as diferenças entre as CCA moída e natural foram entre si em média, 9\%. Pelos resultados obtidos pode-se considerar que as misturas com CCA natural atendem aos requisitos de concreto com boa durabilidade à corrosão da armadura, visto que as condutividades encontradas foram menores do que os REF, que apresentaram o desempenho mais baixo entre todas as misturas, ao contrário do encontrado para a resistividade elétrica.

Deve-se considerar que a resistividade e a condutividade elétricas são propriedades recíprocas, não se podendo estabelecer relação comparativa entre ambas, como no presente estudo, porque os métodos de ensaio são distintos, assim como os valores absolutos das unidades dos resultados, os quais são calculados segundo equações específicas. Diferentemente da resistividade pelo método de Wenner, que é um ensaio de migração elétrica, como mencionado anteriormente, a condutividade específica pelo método de Shi, Stegemann e Caldwell (1998) baseia-se na determinação dos íons presentes na dissolução aquosa de pastas de cimentos ou materiais cimentícios, via análise química, calculando-se os resultados ( $\rho=$ condutividade elétrica da solução aquosa) a partir das condutividades equivalentes dos íons aquosos $\mathrm{Na}^{+}$, $\mathrm{K}^{+}, \mathrm{Ca}^{2+}, \mathrm{OH}^{-}$e $\mathrm{SO}_{4}{ }^{2-}$ numa concentração infinita a $25^{\circ} \mathrm{C}$. Assim, o método dos quatro eletrodos de Wenner determina a resistividade elétrica diretamente pelo equipamento de medição, sendo a condutividade específica calculada indiretamente a partir das condutividades dos principais íons presentes na solução aquosa, especialmente $\mathrm{OH}^{-}$.

\section{Permeabilidade ao $\mathrm{O}_{2}$ e absorção capilar de água}

$\mathrm{O}$ ensaio de permeabilidade ao $\mathrm{O}_{2}$ foi elaborado conforme Kollek (1989) e proposto pelo Cembureau Recommendation para os países europeus, enquanto a absorção capilar de água foi determinada segundo as recomendações do TC116-PCD (RILEM, 1999), cujos resultados encontram-se na Tabela 7 e na Figura 5.

A permeabilidade é um mecanismo de transporte sob pressão e, como a migração e a resistividade/condutividade elétricas, depende da compacidade da microestrutura. As misturas CCAN15, com exceção da resistência $\mathrm{f}_{\mathrm{c} 28-25 \mathrm{MPa}}$, apresentaram as menores permeabilidades ao $\mathrm{O}_{2}$, $\mathrm{O}$ que indicaria comportamento aparentemente paradoxal em relação à cinza moída. Entretanto, a explicação poderia ser a mesma da penetração de $\mathrm{Cl}^{-}$, em que os vazios internos dos grãos da cinza natural serviriam como obstáculo para a continuidade dos poros, o que resultaria em maior obstrução para a permeabilidade desse gás. Para o nível de resistência $25 \mathrm{Mpa}$, a diferença com a CCAM15 é de $-9 \%$, enquanto com a REF é, em média, $-62 \%$. 
Tabela 7 - Permeabilidade ao $\mathrm{O}_{2}$ e absorção capilar de água a 91 dias (REF: I = 100)

\begin{tabular}{c|c|c|c|c}
\hline & $\begin{array}{c}\mathbf{f}_{\mathbf{c 2 8}} \\
\mathbf{M P a}\end{array}$ & REF & $\begin{array}{c}\text { CCA } \\
\text { M15 }\end{array}$ & $\begin{array}{c}\text { CCA } \\
\text { N15 }\end{array}$ \\
\hline Perm. ao $\mathrm{O}_{2}$ & 25 & $2,57-100$ & $1,81-\underline{\mathbf{7 0}}$ & $2,03-79$ \\
$10^{-18} \cdot \mathrm{m}^{2}$ & 30 & $2,16-100$ & $1,36-63$ & $1,05-\underline{\mathbf{4 9}}$ \\
& 40 & $1,34-100$ & $0,64-48$ & $0,35-\underline{\mathbf{2 6}}$ \\
\hline Abs. Cap. & 25 & $2800-100$ & $2150-77$ & $1795-\underline{\mathbf{6 4}}$ \\
água & 30 & $2420-100$ & $2067-85$ & $1571-\underline{\mathbf{6 5}}$ \\
$\mathrm{g} / \mathrm{m}^{2}$ & 40 & $1915-100$ & $1848-97$ & $1257-\underline{\mathbf{6 6}}$ \\
\hline
\end{tabular}

Figura 5 - Permeabilidade ao $\mathrm{O}_{2}$ e absorção capilar água a 91 dias $\times \mathrm{f}_{\mathrm{c28}}$

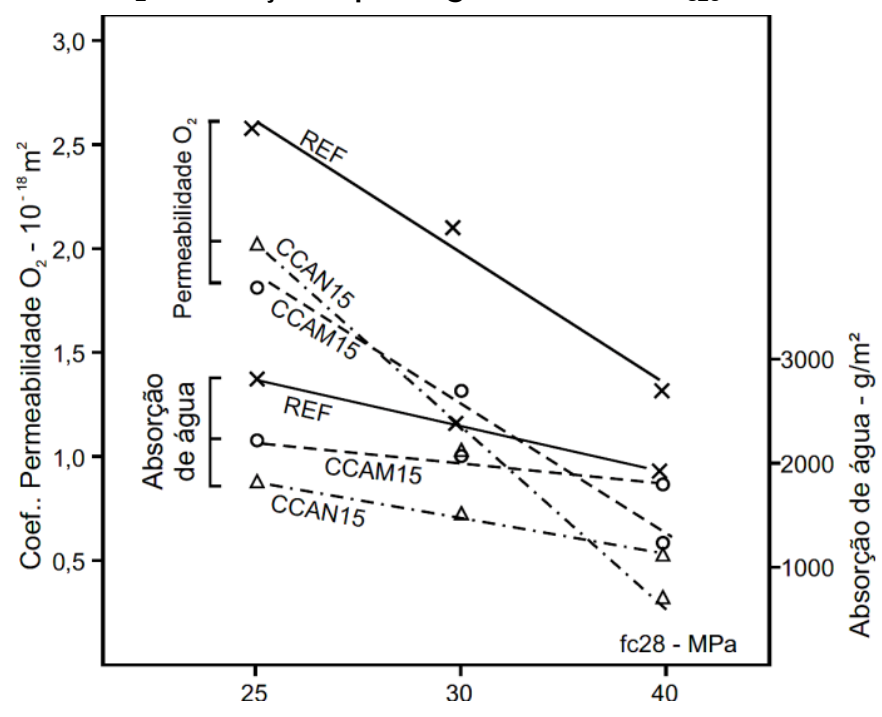

Para a absorção capilar d'água a explicação para o melhor desempenho, novamente, para as misturas CCAN15 poderia ser a mesma anterior, pois o fluxo depende da continuidade dos poros e de seus diâmetros, como no processo de difusão. Assim, como discutido na carbonatação, os poros internos das partículas de cinza natural estariam com água adsorvida em seu interior, o que diminuiria a absorção capilar, como mostra a Tabela 7 . Complementarmente, esses poros internos da cinza natural poderiam sobrepor-se aos canais capilares, diminuindo ou até anulando a tensão superficial nas superfícies das paredes, o que reduziria o fluxo da absorção capilar. Em média, os traços com cinza natural mostraram absorção d'água de $-35 \%$ em relação aos REF e de $-21 \%$ para as misturas CCAM15.

\section{Resistências a ácidos e sulfatos}

Os ensaios de resistência a ácidos foram realizados pela ASTM C267 (AMERICAN..., 2012b) em c.p. de argamassa $5 \times 10 \mathrm{~cm}$ curados em água com cal por 7 dias e, a seguir, em solução de $\mathrm{HCl}$ a $1 \%$, com pesagens até 84 dias. Os ensaios de resistência aos sulfatos seguiram a ASTM C1012 (AMERICAN..., 2004) com c.p. prismáticos de $25 \times 25 \times 285 \mathrm{~mm}$ curados em água com cal por 28 dias (comprimento $\mathrm{L}_{0}$ ), e após em solução de $\mathrm{Na}_{2} \mathrm{SO}_{4}$ a 5\%, com medidas periódicas até 180 dias de exposição.

A penetração das espécies químicas nos poros e vazios capilares processa-se por difusão, que depende da continuidade dos vazios, isto é, da porosidade aberta. Conforme a Tabela 8 e a Figura 6, para os ataques de ácidos e de sulfatos das famílias CCAM15 e CCAN15, a última apresentou menores resultados para as duas variáveis. Pode-se presumir que, além da existência de maior porosidade interior dos grãos da cinza natural, deve-se considerar que as relações $\mathrm{a} / \mathrm{mc}$ dessas últimas foram menores do que as da cinza moída, para atingir o mesmo nível de resistência, conforme ilustra a Tabela 3, logo as porosidades internas foram distintas. Todos os resultados com CCA moída e natural foram menores que o REF, em média $41 \%$ e $47 \%$, para a resistência a ácidos e de $69 \%$ e $79 \%$ para sulfatos respectivamente. 
Tabela 8 - Resistência química ao ataque de ácidos a 84 dias e de sulfatos a 91 dias

\begin{tabular}{|c|c|c|c|c|}
\hline & $\begin{array}{c}\mathbf{f}_{\mathrm{c} 28} \\
\mathbf{M P a}\end{array}$ & REF & $\begin{array}{l}\text { CCA } \\
\text { M15 }\end{array}$ & $\begin{array}{l}\text { CCA } \\
\text { N15 }\end{array}$ \\
\hline $\begin{array}{c}\text { Res. } \\
\text { ácidos } \\
\% \text { - } 84 \mathrm{~d} \text {. } \\
\text { p. massa }\end{array}$ & $\begin{array}{l}25 \\
30 \\
40\end{array}$ & $\begin{array}{l}61,4-100 \\
51,5-100 \\
38,6-100\end{array}$ & $\begin{array}{c}41,8-\frac{58}{6} \\
34,2-66 \\
20,3-533\end{array}$ & $\begin{array}{l}37,5-61 \\
27,7-54 \\
16,6-\underline{43}\end{array}$ \\
\hline $\begin{array}{l}\text { Res. sulf. } \\
\% \text { - } 91 \mathrm{~d} . \\
\text { var. dim. }\end{array}$ & $\begin{array}{l}25 \\
30 \\
40\end{array}$ & $\begin{array}{l}1,28-100 \\
1,07-100 \\
0,77-100\end{array}$ & $\begin{array}{c}0,42-33 \\
0,36-34 \\
0,19-25\end{array}$ & $\begin{array}{c}0,3-\underline{29} \\
0,25-\underline{23} \\
0,08-10\end{array}$ \\
\hline
\end{tabular}

Figura 6 - Resistência a ácidos e sulfatos $x \mathrm{f}_{\mathrm{c} 28}$

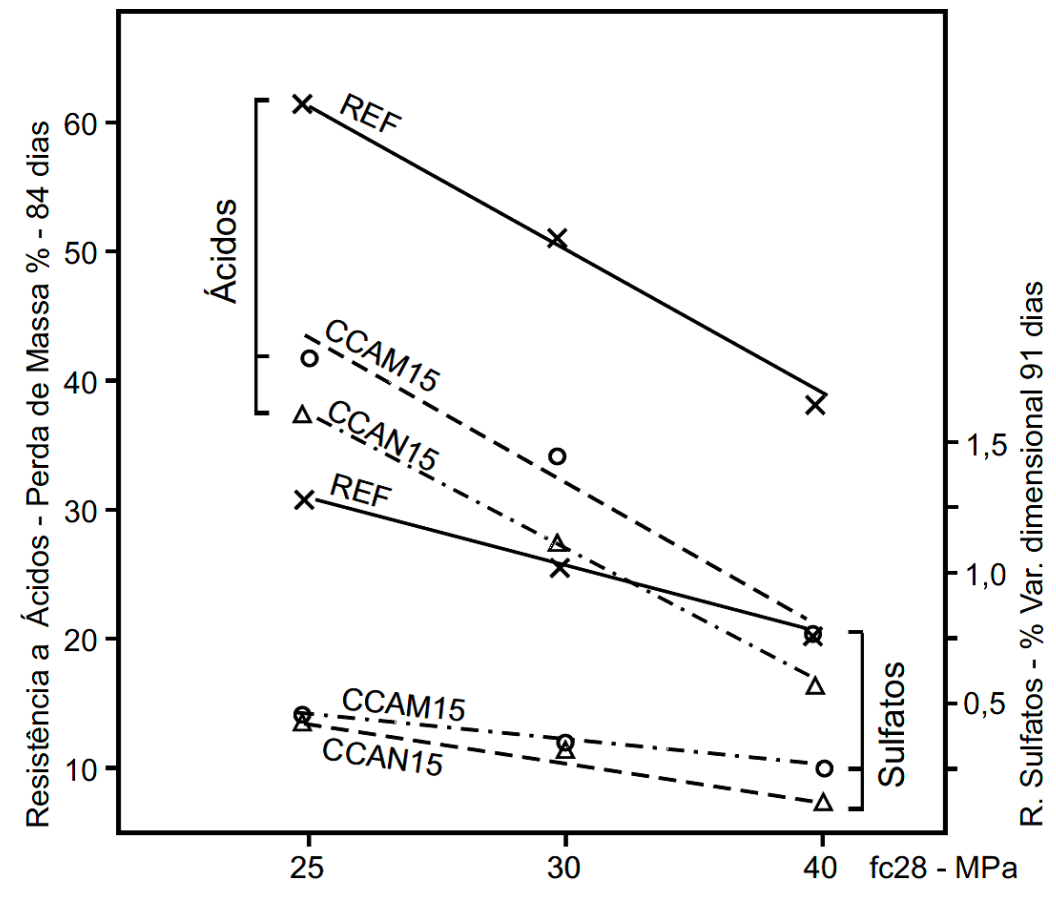

\section{Reação álcali-sílica (RAS)}

Foi realizado o ensaio de expansão de barras de argamassa de $25 \times 25 \times 285 \mathrm{~mm}$ com cimento composto com fíler calcário do tipo CPIIF pelo método acelerado a $80{ }^{\circ} \mathrm{C}$, conforme a NBR 15577-5 (ABNT, 2008b) com CCAM e CCAN, por imersão em solução de $\mathrm{NaOH}$ de $1 \mathrm{~N}$. Os resultados com a cinza natural ficaram acima do limite de expansão de $0,19 \%$ a 30 dias, enquanto com a cinza moída ficaram todos abaixo desse limite. Resultados similares obtiveram Zerbino et al. (2012) e Zerbino, Giaccio e Marfil (2014) em ensaios realizados no Lemit, em La Plata, Argentina, seguindo os mesmos procedimentos desta pesquisa. Os resultados desses ensaios revelam que o tamanho médio dos grãos da CCAN, cerca do duplo da CCAM segundo mostra a Tabela 1, influíram na reatividade da sílica amorfa dos primeiros com os álcalis presentes na pasta do cimento CPIIF, produzindo expansão acima do limite normalizado. Primeiramente se presumiu que a causa dessa expansão poderia ser os grãos de maior dimensão da CCAN, que conteriam maior quantidade de sílica reativa amorfa, os quais funcionariam como agregados reativos, à semelhança das reações álcali- agregado (RAA), produzindo a expansão deletéria. Porém, determinações posteriores com DR-X e MEV com EDS não apresentaram formação de compostos que supostamente seriam responsáveis pelas expansões, denotando-se apenas um tipo de gel expansivo, cuja identificação não foi possível. Estão em curso estudos mais aprofundados nesse tema, conduzidos por Trindade (2011), para pesquisar as prováveis causas desse comportamento da cinza natural, quando utilizadas com cimento sem pozolanas.

É notório que a primeira solução para inibir as reações expansivas entre os álcalis do cimento e as fases amorfas seja dos agregados ou dos materiais cimentícios, como a CCAN do presente estudo, é substituir parte do cimento por pozolanas ou

246 Isaia, G. C.; Zerbino, R. L.; Gastaldini, A. L. G.; Sensale, G. R. 
cimentos pozolânicos, o que, tradicionalmente, tem apresentado resultados benéficos em sua inibição. Para superar essa situação mudou-se o cimento CPIIF, somente com fíler calcário, pelo CPIIZ contendo de $6 \%$ a $14 \%$ de pozolanas, repetindo-se o ensaio anterior com barras de argamassa e encontrando-se redução das expansões dos traços com CCAN ainda acima do limite de $0,19 \%$ a 30 dias (entre $0,7 \%$ e $0,8 \%$ ), enquanto com CCAM atendeu-se ao limite de 16 dias $(<0,1 \%)$, e $<0,19 \%$ a 30 dias, conforme ilustra a Figura 7 . Segundo a norma NBR 15577-1 (ABNT, 2008a), quando o método acelerado de barras de argamassa apresenta expansão acima do teor normalizado $(\geq$ $0,19 \%$ a 30 dias), devem ser realizados ensaios de longa duração de prismas de concreto com dosagem padronizada, segundo a NBR 15577-6 (ABNT, 2008c) para a determinação da reatividade potencial, seja dos agregados (RAA), seja das pozolanas (RAS).

Realizou-se em seguida ensaios de longa duração ( 2 anos, o dobro previsto pela norma NBR 15577 6 (ABNT, 2008c)) com prismas de concreto de $75 \times 75 \times 285 \mathrm{~mm}$, a $38{ }^{\circ} \mathrm{C}$, conforme a NBR 15577 1 (ABNT, 2008a) e a NBR 15577-6 (ABNT, 2008c), cuja expansão não deve ultrapassar 0,04\% para considerar-se a CCAN15 como inócua à RAS. Utilizaram-se também para os traços padronizados cimento com teor padrão de álcalis fornecido pela $\mathrm{ABCP}$, como comparação, e ainda CPIIZ puro, como fornecido pelo fabricante, e ainda com substituição de $10 \%$ e $15 \%$ desse cimento por cinza volante, caso o teor de pozolanas do próprio cimento não fosse suficiente para inibir as reações expansivas da CCAN15.

A Figura 8 mostra que, ao contrário dos resultados dos ensaios com barras de argamassa, todos os traços apresentaram expansões em prismas de concreto inferiores a $0,04 \%$ a 2 anos, com a ordenação ascendente:
(a) cimento padrão;
(b) $\mathrm{CPIIZ}+10 \% \mathrm{CV}+15 \% \mathrm{CCAN}$;
(c) CPIIZ+15\%CCAN; e
(d) CPIIZ+15\%CV+15\%CCAN.

O cimento CPIIZ puro com CCAN15 foi suficiente para mitigar as reações da RAS, o uso de $10 \%$ de CV diminuiu a expansão, e o teor de $15 \%$ aumentou-a. Logo, não é necessária a adição mineral suplementar como a cinza volante quando se usa somente cimento CPIIZ junto com CCAN15, ou outro cimento que contenha pelo menos $14 \%$ de pozolanas, visto que atendeu às condições impostas pela NBR 15577-6 (ABNT, 2008c) (expansão $\leq 0,04 \%$ a 1 ano).

Figura 7 - Expansão em barras de argamassa com CPIIZ pelo método acelerado a $80^{\circ} \mathrm{C}$, segundo a NBR 15577-5:2008

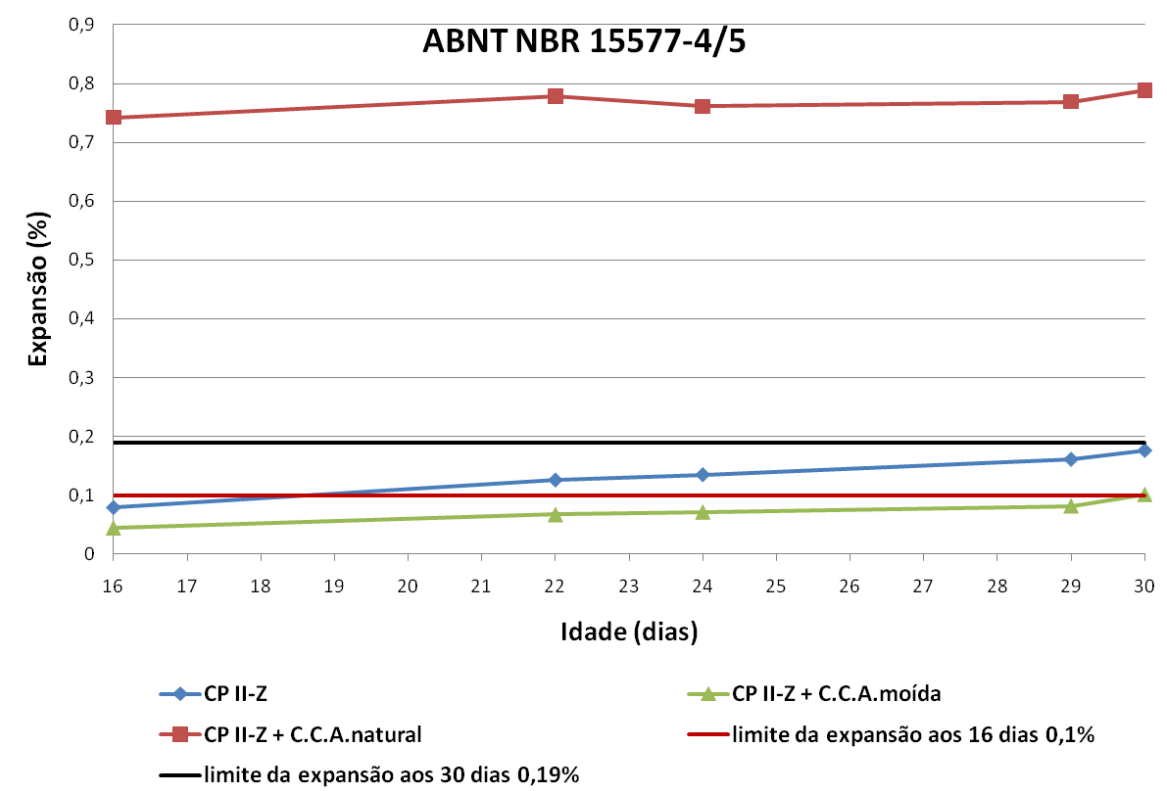

Fonte: Trindade (2011). 


\section{Resumo dos índices dos ensaios de durabilidade (exceto RAS)}

Para análise conjunta das variáveis estudadas, exceto as RAS, transcreve-se na Tabela 9 todos os índices das Tabelas 3 a 8 calculados em relação ao $\mathrm{REF}=100$, para as três famílias de traços, REF, CCAM15 e CCAN15, e os três níveis de resistência à compressão, $\mathrm{f}_{\mathrm{c} 28}=25,30 \mathrm{e} 40 \mathrm{MPa}$; e também as relações $\mathrm{a} / \mathrm{mc}$ que conferiram as resistências à compressão $\mathrm{f}_{\mathrm{c} 91}$, que serviram de base para calcular as regressões (variáveis $\mathrm{x}_{\mathrm{c} 91}$ ). Para cada família de misturas e classe de resistência estão assinalados em negrito, itálico e sublinhado os melhores índices calculados para cada variável, a partir dos resultados dos ensaios, e, ainda, o somatório do número das variáveis que apresentaram os índices mais baixos ou mais altos, conforme a natureza delas. Como este estudo trata da viabilidade de uso de CCA natural, sem processamento, não tendo sido encontrados na literatura parâmetros de comparação sobre a durabilidade do material, o comportamento da família de traços CCAN15 em relação a CCAM15, em seu conjunto representado pela soma das variáveis com melhor desempenho, revela mais claramente o comportamento geral entre ambas, à medida que varia a classe de resistência à compressão. Trata-se de dar visão mais ampla de todos os dados coletados de modo relativo, tornando-os comparáveis entre si e possibilitando discussão mais evidente dos comportamentos individuais e globais de cada família e classe de concreto.

Observa-se que os traços REF apresentaram os menores valores dos coeficientes de carbonatação acelerada e natural em vista dos maiores teores de $\mathrm{CH}$. Os traços CCAM15 se destacaram nas variáveis relacionadas com os processos de migração elétrica (iônica, resistividade e condutividade) para os três níveis de resistência, em vista da maior compacidade da CCA moída na microestrutura da pasta e interfaces pastaagregado, em vista da menor dimensão de seus grãos. Nota-se que a cinza moída foi mais efetiva para as resistências menores (7 variáveis para 25 $\mathrm{MPa}$ ) quando os poros são maiores e mais abertos, enquanto os traços CCAN15 caracterizaram-se pela maior resistência à permeabilidade ao $\mathrm{O}_{2}$, absorção capilar e resistência a ácidos e sulfatos, provavelmente devido à porosidade interna dos grãos de maior dimensão da CCA natural, com possível teor de água aderida aos poros, que obturaram a passagem dos fluidos sob pressão ou capilaridade. Os traços com CCA natural foram mais efetivos para as resistências mais altas (5 variáveis para 30 e $40 \mathrm{MPa})$ também em razão de suas menores relações a/mc.

Figura 8 - Expansão em prismas de concreto pelo ensaio de longa duração a 2 anos a $38^{\circ} \mathrm{C}$, segundo a ABNT NBR 15577-6:2008

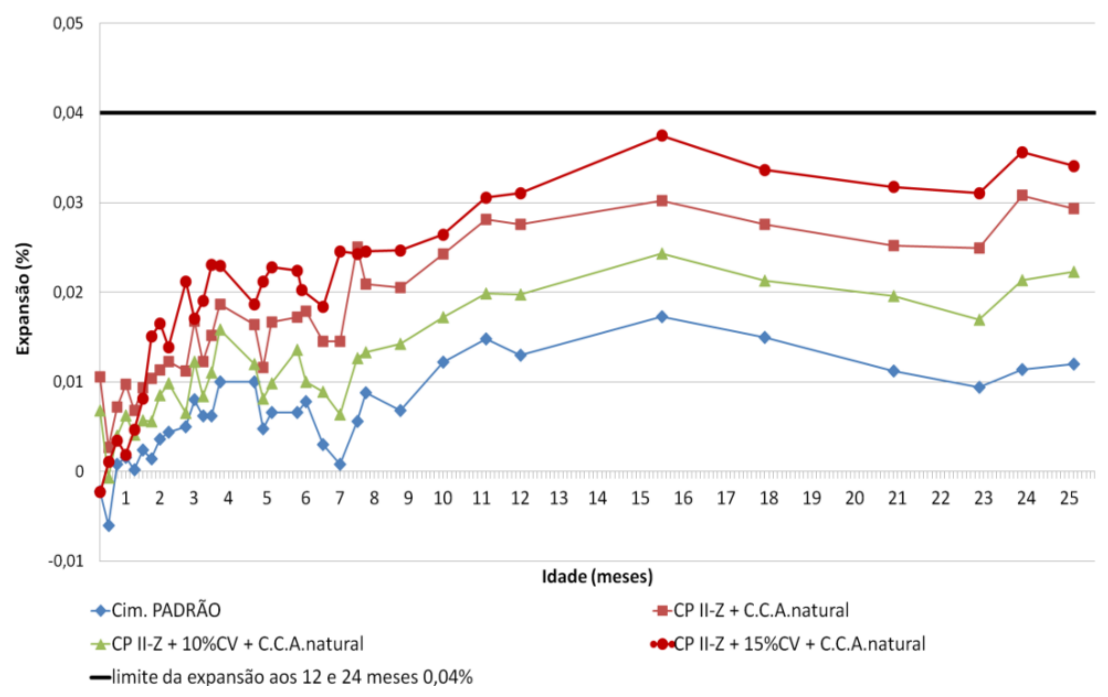

Fonte: Trindade (2011).

248 Isaia, G. C.; Zerbino, R. L.; Gastaldini, A. L. G.; Sensale, G. R. 
Tabela 9 - Resumo dos índices das variáveis de durabilidade $(\mathrm{REF}=100)$

\begin{tabular}{|c|c|c|c|c|c|c|c|c|c|}
\hline VARIÁVEIS DURABILIDADE & \multicolumn{3}{|c|}{ REFERENCIA } & \multicolumn{3}{|c|}{ CCAM15 } & \multicolumn{3}{|c|}{ CCAN15 } \\
\hline $\mathbf{f}_{\mathrm{c} 28} \mathbf{M P a}$ & 25 & 30 & 40 & 25 & 30 & 40 & 25 & 30 & 40 \\
\hline $\mathbf{a} / \mathbf{m c}$ & 0,63 & $\mathbf{0 , 5 6}$ & $\mathbf{0 , 4 6}$ & 0,65 & $\mathbf{0 , 6 0}$ & 0,48 & $\mathbf{0 , 6 1}$ & $\mathbf{0 , 5 3}$ & 0,42 \\
\hline Resistência à compressão $\mathrm{f}_{\mathrm{c} 91} \mathrm{MPa}^{*}$ & 100 & 100 & 100 & $115^{*}$ & 111 & 116 & 111 & $118^{*}$ & $133^{*}$ \\
\hline Carbonatação acelerada 91 dias, mm.sem..$^{-0,5}$ & 100 & 100 & 100 & $\overline{120}$ & 131 & 125 & 114 & 111 & 105 \\
\hline Carbonatação natural 900 dias, mm.ano ${ }^{-0,5}$ & $\underline{100}$ & $\underline{100}$ & $\underline{100}$ & 121 & 127 & 129 & 127 & 120 & 123 \\
\hline Penetração $\mathrm{Cl}^{-} 91$ dias, mm.sem. ${ }^{-0,5}$ & $\overline{100}$ & $\overline{100}$ & $\overline{100}$ & 81 & 82 & 76 & 93 & 81 & 64 \\
\hline Migração iônica 91 dias, coulomb & 100 & 100 & 100 & 61 & 61 & 59 & 71 & 71 & 73 \\
\hline Migração iônica 540 dias, coulomb & 100 & 100 & 100 & 28 & 30 & $\underline{33}$ & 59 & 59 & 59 \\
\hline Resistividade elétrica 91 dias, $\Omega . \mathrm{cm}^{*}$ & 100 & 100 & 100 & $140^{*}$ & $159^{*}$ & 189 & 87 & 86 & 85 \\
\hline Condutividade elétrica 91 dias. $\Omega^{-1}$ & 100 & 100 & 100 & 77 & 78 & 84 & 88 & 89 & 89 \\
\hline Permeabilidade ao $\mathrm{O}_{2} 91$ dias, $10^{-18} \cdot \mathrm{m}^{2}$ & 100 & 100 & 100 & $\underline{70}$ & 63 & 48 & 79 & $\underline{49}$ & $\underline{26}$ \\
\hline Absorção capilar de água 91 dias, $\mathrm{g} / \mathrm{m}^{2}$ & 100 & 100 & 100 & 77 & 85 & 97 & $\underline{64}$ & $\underline{65}$ & 66 \\
\hline Resistência a ácidos 84 dias & 100 & 100 & 100 & 58 & 66 & 53 & 61 & $\underline{54}$ & 43 \\
\hline Resistência a sulfatos 91 dias & 100 & 100 & 100 & 33 & 34 & 25 & 29 & 23 & 10 \\
\hline $\begin{array}{l}\text { Soma das variáveis com os menores } \\
\text { índices }\end{array}$ & $\underline{2}$ & $\underline{2}$ & $\underline{2}$ & $\underline{7}$ & $\underline{4}$ & $\underline{4}$ & $\underline{2}$ & $\underline{5}$ & $\underline{5}$ \\
\hline
\end{tabular}

Nota: *ao contrário das demais, para as variáveis resistência à compressão e resistividade elétrica foram escolhidos os maiores índices porque o desempenho à durabilidade é diretamente proporcional aos valores encontrados nos ensaios.

Com exceção da carbonatação, os traços com CCA natural ou moída apresentaram melhores resultados que os REF. No somatório das três classes de resistências, a família CCAM15 ficou em primeiro lugar, com 15 variáveis, e a CCAN15 em segundo, com 12. Nota-se que os resultados das diferenças dos valores dos ensaios de resistência à compressão e durabilidade, entre os traços com CCA moída e natural, em geral foram inferiores a $20 \%$, o que induz à conclusão de que podem ser utilizados indistintamente em concretos para os níveis de resistência abrangidos pelo estudo. Adiciona-se a essa inferência, à exceção da carbonatação, que tanto a cinza moída quanto a natural apresentaram melhores resultados do que as misturas de referência.

Enfatiza-se que para os traços CCAN15, quando as condições forem propícias para a formação das RAS, é mandatório o uso de cimento composto com pelo menos $14 \%$ de adição pozolânica, como o CPIIZ do presente estudo, ou uso do cimento pozolânico do tipo CPIV.

\section{Conclusão}

O objetivo deste estudo foi verificar a viabilidade de uso da cinza de casca de arroz natural, sem moagem prévia e com moagem dentro da betoneira com os demais materiais durante a mistura. Também foi utilizada cinza de casca de arroz moída em moinho de bolas por $1 \mathrm{~h}$, ambas com a substituição de $15 \%$ de cimento.

Para os ensaios realizados, os valores obtidos para CCAM15 e CCAN15 foram melhores do que os concretos REF, com exceção da carbonatação natural e acelerada.

Para as propriedades de resistência à compressão, penetração de cloretos, permeabilidade ao oxigênio e absorção de água, para as misturas CCAN15 o desempenho foi melhor do que com as CCAM15. Para as propriedades migração iônica, resistividade e condutividade elétrica e resistência aos sulfatos, as famílias de traços CCAM15 apresentaram melhor desempenho, embora as diferenças com as CCAN15 não tenham sido elevadas, em geral inferiores a 20\%, ainda dentro de parâmetros considerados adequados para estruturas de edificações correntes.

As CCAM foram mais efetivas para as propriedades de durabilidade cujas resistência à compressão apresentaram relações a/mc mais altas ( $f_{\mathrm{c} 28}$ na faixa de $25-30 \mathrm{MPa}$ ), enquanto as CCAN para a/mc foram mais baixas ( $\mathrm{f}_{\mathrm{c} 28}$ de $30-40 \mathrm{MPa}$ ).

Os resultados deste estudo permitem concluir que há viabilidade técnica de uso de $15 \%$ de CCAN, sem moagem prévia, em substituição a cimento que contenha pelo menos $14 \%$ de pozolanas, como o CPIIZ deste estudo, devido à possibilidade da ocorrência da RAS, quando utilizados cimentos somente com adição de fíleres do tipo CPIIF.

Além das vantagens técnicas, o uso da cinza de casca de arroz natural diretamente na betoneira aumenta a amplitude de seu emprego, colaborando com a diminuição dos impactos ambientais e a sustentabilidade do concreto estrutural, além de diminuir o custo financeiro desta pozolana pela ausência de moagem. 


\section{Referências}

AMERICAN CONCRETE INSTITUTE. ACI 222.R: protection of metals in concrete against corrosion. Farmington Hills, 2011.

AMERICAN SOCIETY FOR TESTING AND MATERIALS. ASTM C 1202: standard test method for electrical indication of concrete's ability to resist chloride ion penetration. Philadelphia, 2006a.

AMERICAN SOCIETY FOR TESTING AND MATERIALS. ASTM G57: standard teste method for field measurement of soil resistivity using the wenner four-electrode method. Philadelphia, 2012.

AMERICAN SOCIETY FOR TESTING AND MATERIALS. C1012: test method for length change of hydraulic-cement mortars exposed to a sulfate solution. Philadelphia, 2004.

AMERICAN SOCIETY FOR TESTING AND MATERIALS. C267: standard test methods for chemical resistance of mortars, grouts an monolithic surfacing and polymer concretes. Philadelphia, 2006b.

\section{ASSOCIAÇÃO BRASILEIRA DE NORMAS} TÉCNICAS. NBR 11578: cimento Portland composto. Rio de Janeiro, 1991.

ASSOCIAÇÃO BRASILEIRA DE NORMAS TÉCNICAS. NBR 12653: materiais pozolânicos: requisitos. Rio de Janeiro, 2012.

\section{ASSOCIAÇÃO BRASILEIRA DE NORMAS}

TÉCNICAS. NBR 12655: concreto de cimento Portland: preparo, controle e recebimento: procedimento. Rio de Janeiro, 2006.

ASSOCIAÇÃO BRASILEIRA DE NORMAS TÉCNICAS. NBR 15577-1: agregados: reatividade álcali-agregado: parte 1: guia para avaliação da reatividade potencial e medidas preventivas para uso de agregados em concreto. Rio de Janeiro, 2008.

\section{ASSOCIAÇÃO BRASILEIRA DE NORMAS} TÉCNICAS. NBR 15577-5: agregados: reatividade álcali-agregado: parte 5: determinação da mitigação da expansão de barras de argamassa pelo método acelerado. Rio de Janeiro, 2008.

\section{ASSOCIAÇÃO BRASILEIRA DE NORMAS} TÉCNICAS. NBR 15577-6: agregados: reatividade álcali-agregado: parte 6: determinação da expansão em prismas de concreto. Rio de Janeiro, 2008.

\section{ASSOCIAÇÃO BRASILEIRA DE NORMAS} TÉCNICAS. NBR 15877: pintura industrial: ensaio de aderência pro tração. Rio de Janeiro, 2010.
ASSOCIAÇÃO BRASILEIRA DE NORMAS TÉCNICAS. NBR 5736: cimento Portland pozolânico. Rio de Janeiro, 1991.

ASSOCIAÇÃO BRASILEIRA DE NORMAS TÉCNICAS. NBR 5738: concreto: procedimento para moldagem e cura de corpos-de-prova. Rio de Janeiro, 2003a.

ASSOCIAÇÃO BRASILEIRA DE NORMAS TÉCNICAS. NBR 5739: concreto: ensaio de compressão de corpos-de-prova cilíndricos. Rio de Janeiro, 2003b.

ASSOCIAÇÃO BRASILEIRA DE NORMAS TÉCNICAS. NBR 5753: cimento Portland: ensaio de pozolanicidade para cimento Portland pozolânico. Rio de Janeiro, 2010.

ASSOCIAÇÃO BRASILEIRA DE NORMAS TÉCNICAS. NBR 7117: medição da resistividade e determinação da estratificação do solo. Rio de Janeiro, 2012.

ASSOCIAÇÃO BRASILEIRA DE NORMAS TÉCNICAS. NBR 7211: agregados para concreto: especificação. Rio de Janeiro, 2005.

ASSOCIAÇÃO BRASILEIRA DE NORMAS TÉCNICAS. NBR 9779: argamassa e concreto endurecidos: determinação da absorção de água por capilaridade. Rio de Janeiro, 1995.

BROWN, D. K. Unprocessed Rice Husk Ash as a Partial Replacement of Cement For low-Cost Concrete. Cambridge, 2012. Dissertation (Master's Degree) - Massachusetts Institute of Technology, Cambridge, 2012.

CEMBUREAU. Key Facts \& Figures. Disponível em: <http://www.cembureau.eu/about-cement/keyfacts-figures $>$. Acesso em: 16 nov. 2014.

CORDEIRO, G. C. Influence of Particle Size and Specific Surface Area on the Pozzolanic Activity of Residual Rice Husk Ash. Cement and Concrete Composites, v. 33, n. 5, p. 529-534, 2011.

FOOD AND AGRICULTURE ORGANIZATION OF THE UNITED NATIONS. Rice Market

Monitor, v. 16, n. 1, Jan. 2013.

HWANG, C. L.; CHANDRA, S. The Use of Rice Husk Ash in Concrete. In: CHANDRA, S. (Ed.).

Waste Materials Used in Concrete

Manufacturing. Delhi: Standard Publisher Distributors, 2002.

INSTITUTO RIO-GRANDENSE DO ARROZ. Safras. Disponível em: <http://www.irga.rs.gov.br/conteudo/4215/safras>. Acesso em: 16 nov. 2013. 
ISAIA, G. Efeitos de Misturas Binárias e Ternárias de Pozolanas em Concreto de Elevado Desempenho: um estudo de durabilidade com vistas a corrosão da armadura. São Paulo, 1995. 280 f. Tese (Doutorado em Engenharia Civil) - Escola Politécnica da Universidade de São Paulo, São Paulo, 1995.

ISAIA, G. Synergic Action of Fly Ash in Ternary Mixtures With Microsilica and Rice Husk Ash: strength aspects. In: INTERNATIONAL CONGRESS ON THE CHEMISRY OF CEMENT, 10., Gothenburg, 1997. Proceedings... Göteborg: Amarkai AB, 1997.

ISAIA, G. C.; VAGHETTI, M. A.;

GASTALDINI, A. L. G. Carbonatação Acelerada e Natural de Concreto Com Alto Teor de Pozolana: um estudo preliminar. In: CONGRESSO BRASILEIRO DO INSTITUTO BRASILEIRO DO CONCRETO, 43., Foz do Iguaçu, 2001. Anais... São Paulo: Instituto Brasileiro do Concreto, 2001.

ISAIA, G. C.; GASTALDINI, A. L. G.; MORAES, R. Physical and Pozzolanic Action of Mineral Additions on the Mechanical Strength of HPC. Cement \& Concrete and Composites, v. 25, p. 65-72, 2003.

ISAIA, G. C. et al. Viabilidade do Emprego de Cinza de Casca de Arroz Natural em Concreto Estrutural: parte I: propriedades mecânicas e microestrutura. Ambiente Construído, Porto Alegre, v. 10, n. 1, p. 121-137, 2010.

JAMES, J.; RAO, M. B. Reactivity of Rice Husk Ash. Cement and Concrete Research, v. 16, n. 3, p. 296-302, 1986.

KOLEK, J. J. The Determination of Permeability of Concrete to Oxygen by the CEMBUREAU Method: a Recommendation. Materials and Structures, v. 22, p. 225-230, 1989.

MEHTA, P. K. Natural Pozzolans, Supplementary Cementing Materials fOr Concrete. Ottawa: Canadian Government Publishing Centre, Supply and Services, 1987.

MEHTA, P. K.; FOLLIARD, K. J. Rice Husk Ash: a unique supplementary cementing material: durability aspects. ACI Materials Journal, v. 154, 1995.

MEHTA, P. K.; PITT, N. Energy and Industrial Materials From Crop Residues. Resource Recovery and Conservation, v. 2, p. 23-28, 1976.

MEHTA, P. K.; MONTEIRO, P. J. M. Concreto: microestrutura, propriedades e materiais. São Paulo: Ibracon, 2008.
NEHDI, M.; DUQUETTE, J.; EL DAMATTY, A. Performance of Rice Husk Ash Produced Using a New Technology as a Mineral Admixture in Concrete. Cement and Concrete Research, v. 33, n. 5, p. 1203-1210, 2003.

POUEY, M. T. F. Beneficiamento de Cinza de Casca de Arroz Residual Com Vistas a Produção de Cimento Composto e/ou Pozolânico. Porto Alegre, 2006. 329 f. Tese (Doutorado em Engenharia Civil) - Escola de Engenharia, Universidade Federal do Rio Grande do Sul, Porto Alegre, 2006.

QUAMRUDDIN, M.; KALURKAR, L. G. Effect of Unprocessed Rice Husk Ash as a Cementitious Material in Concrete: a comparison with silica fume. International Journal of Civil

Engineering and Technology, v. 4, n. 2, p. 240245, 2013.

RÊGO, J. H. S. As Cinzas de Casca de Arroz Amorfa e Cristalina Como Adição Mineral ao Cimento: aspectos de microestrutura das pastas. Brasília, 2004. 274 f. Tese (Doutorado em Engenharia Civil) - Escola de Engenharia, Universidade de Brasília, Brasília, 2004.

RILEM. Recommendation TC 116-PCD. Tests for gas permeability of concrete. Determination of the capillary absorption on water of hardened concrete. Materials and Structures, v. 32, n. 217 , p. 163-179, 1999.

RILEM. CPC-18: measurement of hardened concrete carbonatio depth. Materials and Structures, v. 21, n. 126, p. 453-455, 1988.

RODRIGUES, S. G. High Performance Concrete With Residual Rice Husk ash. In: DHIR, K. R.; NEWLANDS, M.; PAINE, K. (Eds.). INTERNATIONAL SYMPOSIUM DEDICATED TO PROF. SURENDRAH SHAH, Dundee, 2003. Proceedings... London: Thomas Telford, 2003.

SENSALE, G. R. B. Estudo Comparativo Entre as Propriedades Mecânicas dos Concretos de Alta Resistência e Convencionais Com Cinza de Casca de Arroz. Porto Alegre, 2000. 182 f. Tese (Doutorado em Engenharia Civil) - Escola de Engenharia, Universidade Federal do Rio Grande do Sul, Porto Alegre, 2000.

SHI, C.; STEGEMANN, J. A.; CALDWELL, R. J. Effect of Supplementary Cementing Materials on the Specific Conductivity of Pore Solution and This Implications on the Rapid Chloride Permeability Test (AASHTO T277 and ASTM C1202) Results. ACI Materials Journal, Farmington Hills, v. 95, n. 4, p. 389-394, 1998.

SMAJILA, M. Rice Husk Ash in Concrete. Saarbrücken: Lambert, 2010. 
SINDICATO NACIONAL DA INDÚSTRIA DO CIMENTO. Produção Nacional de Cimento por Regiões e Estado. Disponível em: <http://www.snic.org.br/numeros/produ\%C3\%A7a o-regional-2012.htm>. Acesso em: 16 nov. 2014.

SUGITA, S.; SHOYA, M.; TOKUDA, H. Evaluation of Pozzolanic Activity of Rice Husk Ash. In: INTERNATIONAL CONFERENCE ONFLYASH, SILICA FUME, SLAG AND NATURAL POZZOLANS INCONCRETE, 4 ., Istanbul, 1992. Proceedings... Istambul, 1992.

TRINDADE, G. H. Durabilidade do Concreto Com Cinza de Casca de Arroz Natural Sem Moagem: mitigação da reação álcali-sílica e penetração de cloretos. Santa Maria, 2011. 198 f. Dissertação (Mestrado em Engenharia Civil) Escola de Engenharia, Universidade Federal de Santa Maria, Santa Maria, 2011.

TUAN, B. L-A. The use of black rice husk ash in concrete. Saarbrücken: Lambert, 2012.
ZERBINO, R. et al. Alkali-Silica Reaction in Mortars and Concretes Incorporating Natural Rice Husk Ash. Construction \& Building Materials, v. 36, p. 796-806, 2012.

ZERBINO, R.; GIACCIO, G.; MARFIL, S.

Evaluation of Alkali-Silica Reaction in Concretes With Natural Rice Husk Ash Using Optical Microscopy. Construction \& Building Materials, v. 71, p. 132-140, 2014.

ZHANG, M. H.; MALHOTRA, M. HighPerformance Concrete Incorporating Rice Husk Ash as a Supplementary Cementing Material. ACI Materials Journal, v. 93, n. 6, p. 629-636, 1996.

\section{Agradecimentos}

Os autores agradecem ao CNPq/Programa Prosul, pelo apoio financeiro para a realização desta pesquisa, e à Capes, Fapergs e CNPq pelas bolsas ofertadas. Este projeto teve a coordenação geral do primeiro autor e dos coordenadores locais, Prof. Raúl Zerbino, do Lemit-CIC, La Plata, Argentina, e da Profa. Gemma Sensale, da Universidad de La República, Montevideu, Uruguai.

\section{Geraldo Cechella Isaia}

Departamento de Estruturas e Construção Civil, Centro de Tecnologia | Universidade Federal de Santa Maria | Av. Roraima, 1000, Cidade Universitária, Camobi | Santa Maria - RS - Brasil | CEP 97119-900 | Tel.: (55) 220-8000 Ramal 8144 | E-mail: gisaia@terra.com.br

\section{Raúl Luis Zerbino}

Laboratorio de Entrenamiento Multidisciplinario para la Investigación Tecnológica | Comisión de Investigaciones Científicas | 52 entre 121 y 122 | La Plata - Buenos Aires - | Argentina | CP 1900 | Tel.: + 54 (221) 483-1142 | E-mail: zerbino@unlp.edu.ar

\section{Antonio Luiz Guerra Gastaldini}

Departamento de Estruturas e Construção Civil, Centro de Tecnologia | Universidade Federal de Santa Maria | RS 509 km 9, Camobi | Santa Maria - RS - Brasil | CEP 97105-900 | Tel.: (55) 3220-8144 Ramal 8144 | E-mail: gastaldini@pq.cnpq.br

\section{Gemma Rodrigues Sensale}

Instituto de Ensayos de Materiales, Facultad de Ingenieria | Universidad de la República | Julio herrera y Reissig, 565 | Montevideo Uruguay | CEP 11300 | Tel.: +59 (82) 711-7435 | E-mail: gemma@fing.edu.uy

\section{Revista Ambiente Construído}

Associação Nacional de Tecnologia do Ambiente Construído

Av. Osvaldo Aranha, $99-3^{\circ}$ andar, Centro

Porto Alegre - RS - Brasil

$$
\text { CEP } 90035-190
$$

Telefone: +55 (51) 3308-4084

Fax: +55 (51) 3308-4054

www.seer.ufrgs.br/ambienteconstruido

E-mail: ambienteconstruido@ufrgs.br

252 Isaia, G. C.; Zerbino, R. L.; Gastaldini, A. L. G.; Sensale, G. R. 